\title{
Shell Mounds as the Basis for Understanding Human-Environment Interaction in Far North Queensland, Australia
}

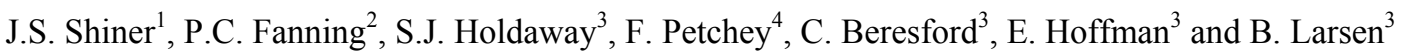

1 Rio Tinto Alcan Pty Ltd, 123 Albert Street, Brisbane QLD 4000, Australia Justin.Shiner@riotinto.com

2 Department of Environment and Geography, Macquarie University, NSW 2109, Australia patricia.fanning@mq.edu.au

3 Department of Anthropology, The University of Auckland, Private Bag 92019, Auckland 1142, New Zealand sj.holdaway@auckland.ac.nz, cal1047@aucklanduni.ac.nz, ehof004@aucklanduni.ac.nz, blar020@aucklanduni.ac.nz

4 Waikato Radiocarbon Dating Laboratory, University of Waikato, Private Bag 3240, Hamilton, New Zealand fpetchey@waikato.ac.nz

\begin{abstract}
The Weipa shell mounds have a long history of archaeological research that has made a significant contribution to our understanding of the emergence of late Holocene coastal economies in northern Australia. However, much of this work has focused on broad comparisons of mounds between multiple locations rather than detailed studies of multiple mounds from single locations. This level of analysis is required to understand the record of both human occupation and environmental change and how these have given rise to the form of archaeological record visible in the present. In this paper we describe the results of a recent pilot study of four Anadara granosa-dominated shell mounds at Wathayn Outstation near Weipa in far north Queensland. We adopt a formational approach that investigates variability in shape, size, orientation, stratigraphy, shell fragmentation and diversity and mound chronology, as well as dating of the surfaces upon which the mounds have been constructed. Results indicate multiple periods of shell accumulation in each mound, separated by hiatuses. The mounds are the end product of a complex mix of processes that include how often and how intensively mounds were used and reused, together with the nature of the shell populations that people exploited and the post-depositional environmental changes that have occurred over the centuries the mounds have existed.
\end{abstract}

\section{Introduction}

Adaptation to climate change is nothing new for Aboriginal Australian people, having occupied the continent for more than 40,000 years. However, this longterm survival was only achieved by people locally responding in a variety of ways to shifts in environmental conditions. Understanding the nature of these responses provides one way of framing the Aboriginal history of habitation of local areas, as well as of the continent. This issue is particularly topical given contemporary concerns with how modern human populations might respond, and adapt, to climate change. To develop such a history requires detailed, integrated study of both the record of human occupation and the history of environmental change on local and regional scales and how both have given rise to the form of archaeological record that we see today.

The area around Weipa in the tropical far north of Queensland, Australia (Figure 1), well-known in Australian archaeology for its shell mounds, is an ideal location to undertake such a study. Recent archaeological work in the region indicates a record of both coastal and inland human occupation dating to at least the late Holocene (Bailey 1999; Shiner and Morrison 2009) which offers the opportunity to develop detailed environmental histories, including that of sea-level change, identified through the sedimentological, biological and stratigraphic records preserved in wetlands, estuaries and beach ridges. Coastlines are important places for humans because, as classic ecotones, they were productive and rich in biodiversity, resulting in the adoption of a variety of resource exploitation strategies by people in the past
(Bailey and Parkington 1988). Coastlines are also geomorphologically active, and frequently preserve a detailed record of past sea-level fluctuations and environmental change (e.g. Bailey 2004; Chappell and Grindrod 1984; Sloss et al. 2005, 2006, 2007). At Weipa seasonal contrasts are marked by effectively arid conditions (i.e. hot and dry) from May to November, followed by plentiful rainfall from December to April.

Northern Australia has experienced shifts in environmental variables in the past that influenced Aboriginal people to change, from time-to-time, the way they obtained resources (Bourke et al. 2007; Haberle and David 2004). Food resources such as shellfish are particularly susceptible to the effects of environmental change, particularly sea-level change (Bailey et al. 1994). Resources obtained inland from the Eucaplyptus tetrodonta woodland and remnant notophyll vine scrub of the bauxite plateau are also likely to have changed in abundance in response to shifts in local environmental conditions, including the frequency and intensity of fire (Crowley 1995). Recent studies from Queensland also suggest major shifts in resource use as a result of longerterm environmental changes. Cosgrove et al. (2007), for instance, discuss movement of people into the Queensland rainforest. Their study suggests that similar long-term shifts in the environment might lead to changes in resource exploitation by the people of western Cape York. It is necessary therefore to consider the relative impact on resource abundance of local versus regional shifts in the environment. It is also necessary to consider the impact that environmental changes had on the way the archaeological record was formed and preserved. 


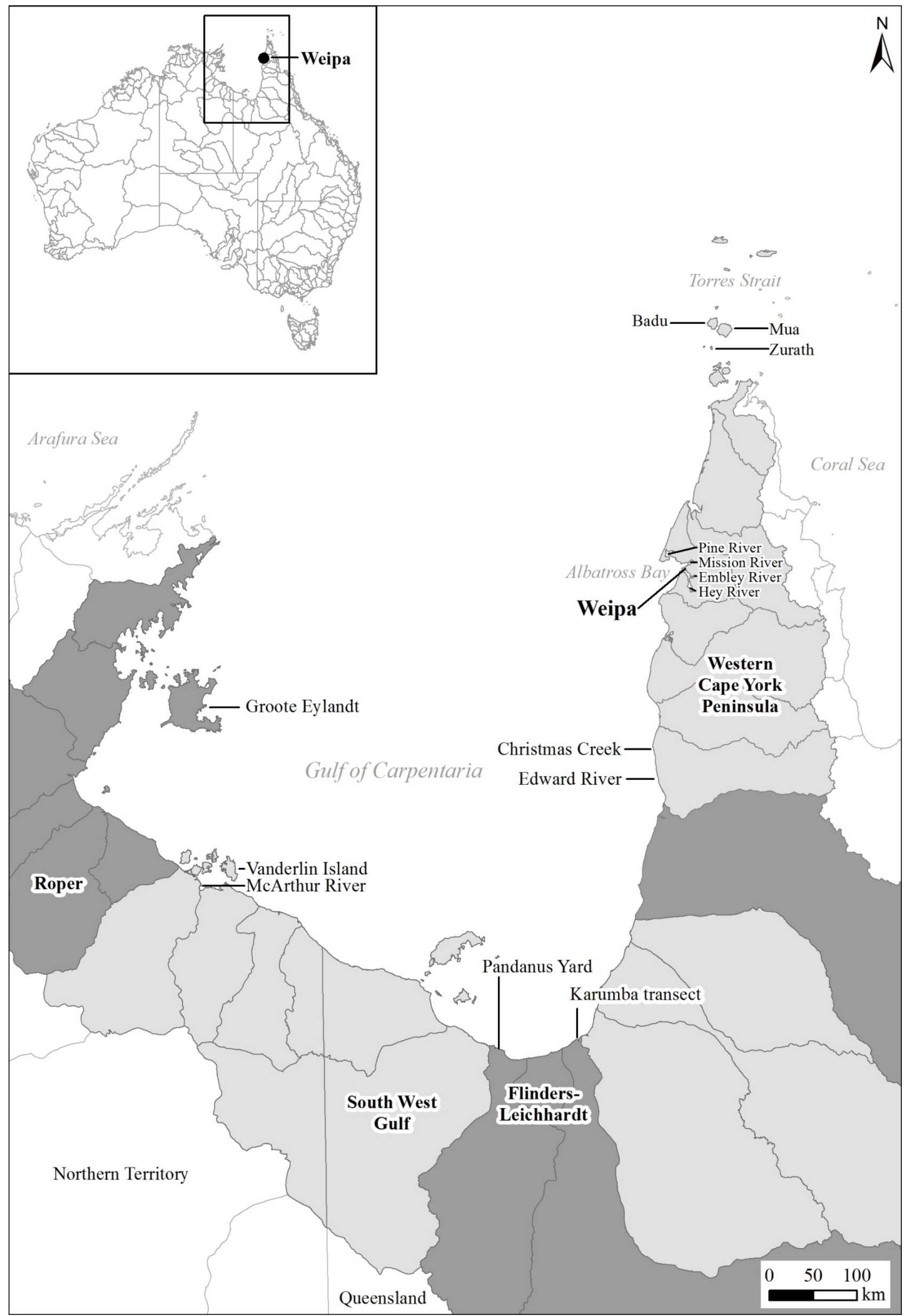

Figure 1. Gulf of Carpentaria showing drainage divisions, and locations of places mentioned in the text. 


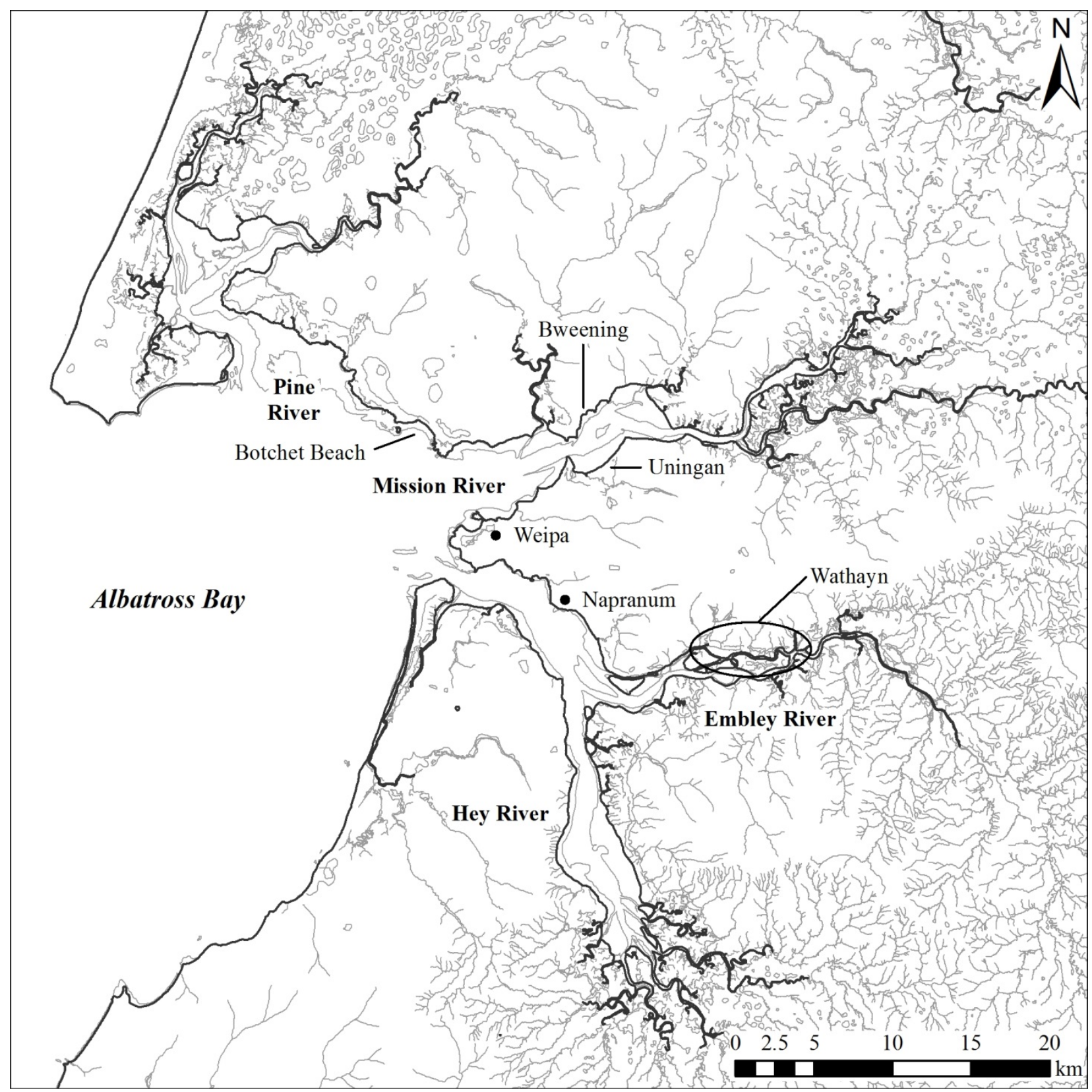

Figure 2. Albatross Bay showing the location of the Wathayn study area.

In this paper we present the results of a preliminary study of aspects of the archaeological and environmental record at the Wathayn Outstation, located approximately $25 \mathrm{~km}$ east of Weipa (Figure 2), which we used as a pilot research programme to develop the scope and methods for a more extensive project investigating the spatial and temporal record of human-environment relationships along the northern bank of the Embley River. Understanding the formational history of the archaeological record is a critical consideration of our approach, especially the local effects of macro-scale processes on the preservation and exposure of the record we see in the present.

\section{The Cultural Heritage Context}

While shell mounds in the Weipa area were first described by Roth in 1901, their considerable size and spatial extent only began to be recorded in the 1960s, with the work of Richard Wright (1964, 1971), followed in the early 1970s by Geoff Bailey (1975a, 1977) who comprehensively surveyed the estuaries of Albatross Bay. This early work (see also Bailey 1983, 1999; Cribb 1986; Morrison 2003) coincided with the first geological descriptions of bauxite across the western Cape York area beginning in the 1950s. Mining soon followed with the establishment of the Comalco (now Rio Tinto Alcan) mine at Weipa in the early 1960 s, followed by a second mine at Andoom in 1972. Bauxite deposits are extensive and mining has the potential to continue for many decades. Since 2003 a programme of cultural heritage assessment across the Rio Tinto Alcan leases has mapped over 5000 cultural heritage sites consisting of culturally modified trees, surface stone artefact scatters, shell mounds, earth mounds, ethnographic places and historic sites (Shiner and Morrison 2009). These surveys, focussed on the bauxite plateau, have demonstrated that the archaeological and the cultural heritage record of the area is far more extensive and complex than previously understood from research focussed only on shell mounds within the coastal zone. 


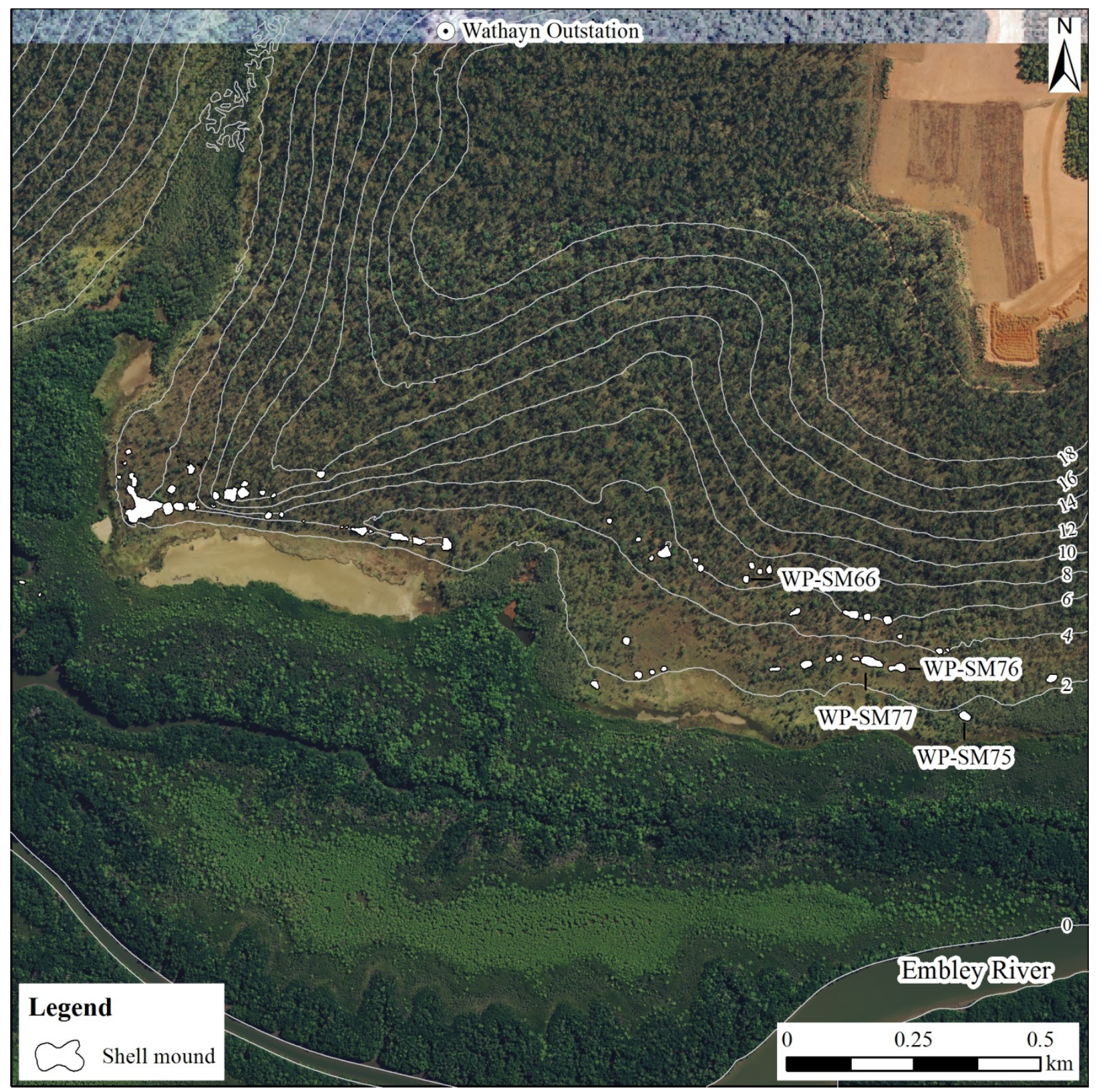

Figure 3. The Wathayn study area showing the location of the outstation building, the mine site, and the four analysed shell mounds (labelled) relative to other mounds in the vicinity (white dots). Contour interval (white lines) is $2 \mathrm{~m}$.

Combined with previous research on shell mounds, the data from the plateau surveys presented a more comprehensive, but also constrained, picture of the archaeological record. The impact-orientated compliance focus of these surveys meant that very little additional knowledge could be gleaned of the environmental and archaeological contexts of these new discoveries. In addition, not all areas are directly impacted by mining, meaning that many areas of importance to contemporary traditional owners, such as the coastlines and estuaries, have not been adequately investigated. Missing from this process is a longer-term strategy to focus cultural heritage investment and subsequent management onto those parts of the landscape that are of priority and interest to contemporary traditional owners. Key to this is directing cultural heritage practice to documenting the history of the land.

68 | $2013 \mid$ Vol. 16 | q a r
The aim of the larger research project, of which this pilot study forms a part, is to develop such a process through a research partnership with Rio Tinto Alcan and the traditional owners of the Weipa region. Outcomes will include detailed palaeoenvironmental reconstruction and assessment of how Indigenous populations adapted to changes in environmental conditions in the western Cape York region in the past. This knowledge will allow more informed decisions to be made about how the legacy of that occupation can best be managed in the contemporary context of shared responsibility between indigenous traditional owner groups and the mine operators.

We are currently developing this approach with Wathayn traditional owners at their main outstation situated on the northern side of the Embley River (Figures 2-3). Wathayn is an important location for the traditional owners, most of whom reside in the nearby community of 
Napranum. The outstation, consisting of several buildings situated above a spring-fed creek, is occupied on a semipermanent basis during the dry season. The area around the outstation contains hundreds of archaeological and culturally important sites. Wathayn traditional owners continue to hunt in the area, especially for wild pigs, fish in the river and collect shellfish from the mangroves that line the shores. Numerous small contemporary shell middens continue to be made around the outstation and on the estuarine floodplain near the river. Through geomorphic mapping of landforms and excavation and analysis of shell mounds, and by working closely with Wathayn traditional owners, this research programme will create a narrative of the dynamic cultural history of the region.

\section{Regional and Local Palaeoenvironmental Contexts}

Study of past human-environment interactions in the region necessarily begins with an account of recent sealevel change because of the close relationship between people and the sea, especially the food resources it provides. Prior research indicates that there is an overall trend of coastline regression within the Gulf of Carpentaria from the mid-Holocene to the present-day (Beresford 2011). Previous research in the FlindersLeichhardt region in the south and the western Cape region in the north (Figure 1) indicates that sea-level fell from a maximum of $2.58 \mathrm{~m}$ above present mean sea level (PMSL) at c.6000 cal BP, to $1 \mathrm{~m}$ above PMSL c.1750 cal BP. Sea-level continued to fall to within $0.5 \mathrm{~m}$ of PMSL by c.600 cal BP. Rhodes (1980) and Chappell et al. (1982) attribute relative sea-level fall within the Gulf of Carpentaria during the mid-Holocene to increased water loading on the eastern Australian continent. During the most recent post-glacial marine transgression, rising sealevels produced isostatic emergence of between $0.2 \mathrm{~m}$ and $1.4 \mathrm{~m}$ for the Edward River region of western Cape and between $1.7 \mathrm{~m}$ and $3.1 \mathrm{~m}$ around Karumba in the FlindersLeichhardt region (Chappell et al. 1982). Recalibrated radiocarbon age determinations place the initiation of marine regression earlier in the Holocene, c.7000-6000 cal BP (Beresford 2011). Relative Holocene sea-level fall at Albatross Bay as a consequence of isostatic emergence along the western Cape York coast is therefore estimated at $1-2 \mathrm{~m}$ above PMSL since $6500 \mathrm{cal} \mathrm{BP}$ (Chappell et al. 1982; Lambeck and Nakada 1990).

Sea-level change and hydrological response within the Gulf of Carpentaria appear to be causally linked (Shulmeister and Lees 1995). The breach of the Torres Strait by the Arafura Sea (c.8000 cal BP) re-established ocean-atmospheric teleconnections between the Gulf of Carpentaria and the Pacific Ocean (Reeves 2004), coinciding with a general increase in precipitation effectiveness which is thought to signal the initiation of the Australian Monsoon (Wyrwoll and Miller 2001). Across the Gulf of Carpentaria there is latitudinal variation in the onset, duration, and cessation of different climatic conditions. For example, the earliest date for the onset of wet conditions at Mua, in the Torres Strait, is $7635 \pm 45$ cal BP, while at Vanderlin Island in the south it is dated at $4719 \pm 77 \mathrm{cal} \mathrm{BP}$ (Beresford 2011).

From 4000-3000 cal BP onwards, increased seasonal variability in the reliability and effectiveness of precipitation is widely attributed to the initiation of the El
Niño Southern Oscillation (ENSO) (Anderson et al. 2007; McGlone et al. 1992; Shulmeister and Lees 1992; Wanner et al. 2008). However ENSO signals are differently expressed according to regional latitude (McGlone et al. 1992). Hydrological data from the western Cape region suggests higher rainfall and a relatively late transition to the present drier regime c.1000 cal BP. In contrast, the latest dry phase at Vanderlin Island, the most southerly location, initiates at c.3000 cal BP (Beresford 2011).

Local coastal geomorphology is also the consequence of Holocene sea-level change and large-scale climate processes operating across the Gulf of Carpentaria. Beaches and chenier ridges form seaward as a result of the dominance of wave-induced sediment transport and sorting processes, while high fluvial activity with associated high terrigenous sediment flux results in deposition of fine muddy sediments in estuaries (Rhodes 1980). The formation of beach and chenier ridges signals a perturbation to the dominant mode of sediment transport to the coast. Beach ridges at Christmas Creek, Edward River and Botchet Beach, for example, show a very high correlation with each other, their formation occurring within three periods: 7000-6000 cal BP, 4000-3000 cal BP and c.2000 cal BP (Beresford 2011). Chenier ridge plains at Karumba and Pandanus Yard follow a similar depositional history to the beach ridges. However, during the period 4500-2000 cal BP, it appears that system connectivity between the eastern and southern regions of the Gulf of Carpentaria decreased, producing different coastal landforms at different times. At c.3200-3500 cal $\mathrm{BP}$, for example, beach and chenier ridges form in many parts of the Gulf of Carpentaria, followed by a change in the rate of progradation. For southern Gulf regions, this transition is indicated by a slight increase in muddy sediment supply to the coast. In contrast, the rate of progradation in the north decreases, signalling a reduction in sediment deposition. Local progradation is in part controlled by hydrological processes (both marine and fluvial) influencing sediment supply and accommodation.

The cockle Anadara granosa, the shells of which make up the bulk of the Weipa shell mounds, require muddy sediment to occur within the intertidal range, with a low gradient and with shelter from shoreward currents (Bailey et al. 1994). Mangrove estuaries provide conditions suitable for $A$. granosa colonisation and growth (Broom 1985). Mangrove taxa (i.e. Rhizophoraceae) identified from published palynological research demonstrates that mangroves are present throughout the Holocene in at least one region within the Gulf of Carpentaria (Beresford 2011). However, the coarse chronology means that mangrove presence is not a useful proxy indicator of $A$. granosa. Nor is the presence of A. granosa correlated with either presence or absence of mangrove pollen. Radiocarbon age determinations on A. granosa show the species to be present within the Gulf of Carpentaria from at least c.5000 cal BP and at Albatross Bay from at least c. 2400 cal BP (Beresford 2011). At Albatross Bay, the ages of A. granosa correlate with the infilling of estuaries with muddy sediment such that older samples are further upstream from the coast. These results are consistent with the findings of Woodroffe and Chappell (1993) for the McArthur River delta. 


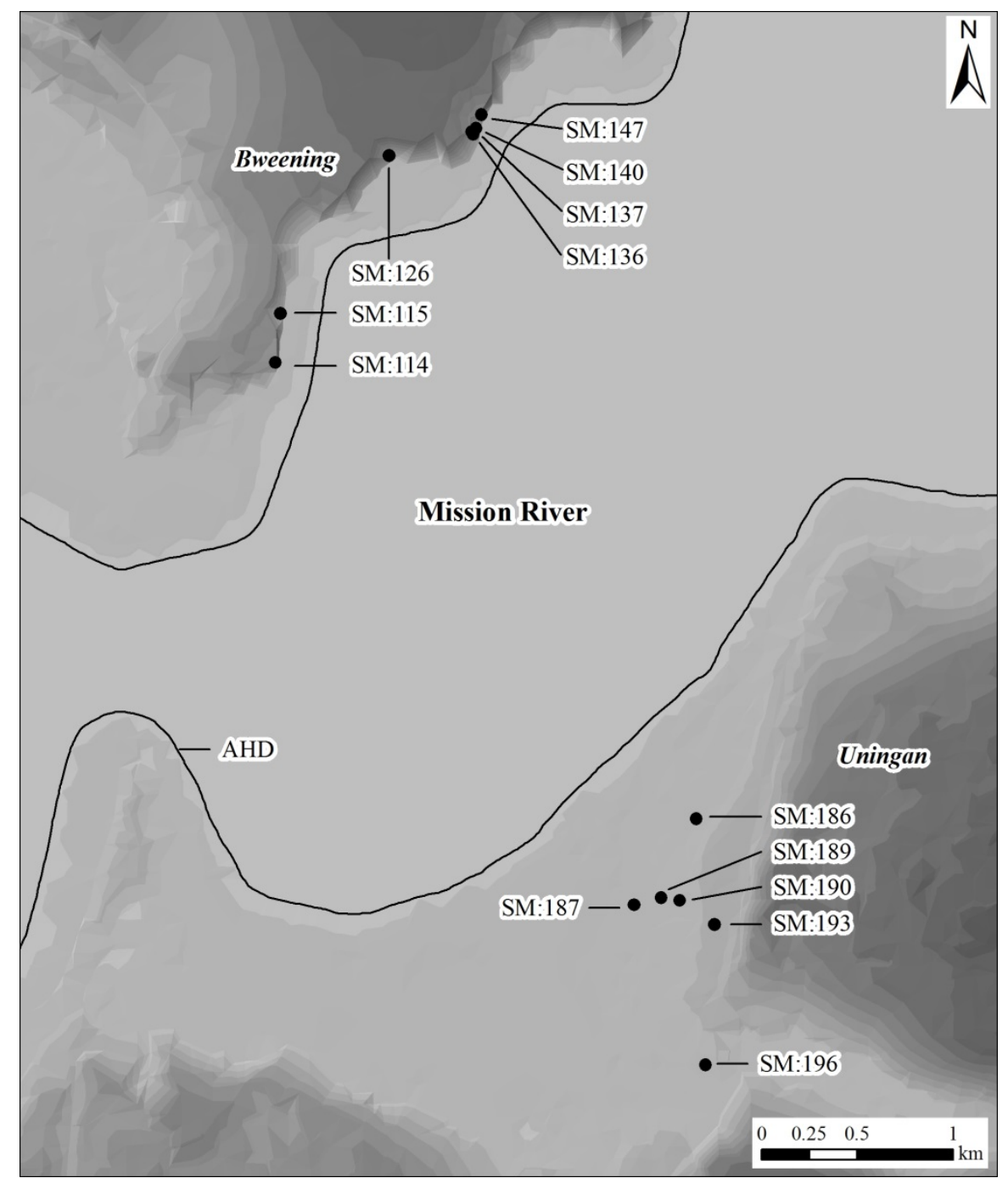

Figure 4. Digital elevation model (DEM) showing locations of dated shell mounds at Bweening and Uningan on the Mission River (from Beresford 2011). Shell mound numbering corresponds with those assigned by Morrison (2010). LiDAR data (flown 2011) provided by Rio Tinto Alcan Pty Ltd.

Comparison of two areas on the Mission River (Figure 4) demonstrates the importance of taking into account the fluvial geomorphic history in understanding initial conditions for shell mound construction by people. Processes such as sedimentation and erosion deposit, remove and rework coastal landforms. These processes have implications for the position of $A$. granosa colonisation, growth of beds for shellfish collection by people, the availability of land surfaces for shellfish discard by people, and the post-depositional removal of coastal and archaeological features. The landscape at Bweening on the northern edge of the Mission River features a steep escarpment from the bauxite plateau to the river edge, an area of active erosion by waves in the past (Morrison 2010:184). In contrast, Uningan on the southern shore is characterised by $1.5 \mathrm{~km}$ of prograded mudflat. At Bweening, only those shell mounds that are beyond the extent of present-day maximum sea-level and tidal incursion remain. At Uningan, in contrast, morphological and spatial characteristics of shell mounds show little relationship to modern river proximity (but see Stone 1995). At this location, surface dates suggest two periods of final accumulation, at 700-800 cal BP and 400-100 cal BP, reflecting patterns of sea-level change, sediment accumulation and the timing of tidal events.
Around the Australian coastline, archaeological sites have been used to model past indigenous social use of landscape (Smith 1996), demographic growth, population shifts and social intensification (Beaton 1985; Lourandos 1985), and for evaluating responses to climate change (Turney and Hobbs 2006). However, the coastal archaeological record is potentially modified by natural events such as higher sea-levels, cyclones, storm surges and other marine inundation events. As discussed above, stability in coastal landforms also plays a major role in coastal archaeological sites survival through time. These natural processes, that may have macro-regional causes but which interact in complex ways to produce local outcomes, may impact on the preservation, exposure and visibility of the remaining archaeological record and must be understood if the material record and chronologies from coastal archaeological sites are to be regarded as an accurate reflection of past human land-use and responses to climate variations. Despite the long history of shell mound investigation in the Weipa region, there is a notable lack of taphonomic studies connected with mound presence and preservation. To a large degree, the location, composition and form of shell mounds are accepted at face value. Our study was in part designed to fill this gap in knowledge. 
Table 1. Characteristics of Wathayn mound substrate samples.

\begin{tabular}{|l|c|c|c|c|c|r|r|}
\hline Mound \# & $\begin{array}{c}\text { Organic } \\
\text { Content } \\
(\%)\end{array}$ & $\begin{array}{c}\text { Carbonate } \\
\text { Content } \\
(\mathbf{\%})\end{array}$ & $\begin{array}{c}\text { Moisture } \\
\text { Content } \\
(\mathbf{\%})\end{array}$ & $\begin{array}{c}\text { Mineral } \\
\text { Content } \\
(\%)\end{array}$ & $\begin{array}{c}>300 \boldsymbol{\mu m} \\
\mathbf{( \% )}\end{array}$ & $\begin{array}{c}\mathbf{3 0 0}-\mathbf{6 3} \boldsymbol{\mu m} \\
\mathbf{( \% )}\end{array}$ & $\begin{array}{c}<63 \boldsymbol{\mu m} \\
\mathbf{( \% )}\end{array}$ \\
\hline WPSM66 & 5.072 & 0.478 & 5.501 & 88.949 & 68.232 & 16.968 & 14.8 \\
\hline WPSM75 & 10.214 & 0.747 & 18.449 & 70.590 & 33.932 & 15.868 & 50.2 \\
\hline WPSM76 & 2.868 & 0.007 & 3.890 & 93.234 & 62.997 & 31.603 & 5.4 \\
\hline WPSM77 & 2.381 & 0.062 & 4.545 & 93.012 & 60.599 & 34.601 & 4.8 \\
\hline
\end{tabular}

\section{The Study Area}

The Wathayn study area (Figure 3) is bounded to the north by the bauxite plateau of the Weipa Peninsula, to the south by the Embley River, and to the east and west by unnamed, spring-fed freshwater streams. The land slopes relatively gently from the plateau to the distal margin of the estuarine floodplain in the eastern (upstream) part of the study area, but in the west (downstream) the slopes terminate in a steep drop falling up to $10 \mathrm{~m}$ to the floodplain below. The shell mounds described in this paper are located at the eastern section (Figure 3), on a variety of geomorphic features and substrates, as described below.

Eucalyptus tetradonta woodland, with an understory of dense shrubs and grasses, forms a continuous vegetation cover across the slopes. On the estuarine floodplain, the vegetation cover consists of discontinuous patches of paperbark around the mouths of tributaries, and salt-tolerant species such as Salicornia sp. A dense fringe of mangrove forest growing in a mud-dominated substrate separates the distal floodplain from the open water of the Embley River (Figure 3). While the slopes are by and large soil-mantled, and termite mounds are prominent, a low (to $1 \mathrm{~m}$ high) bauxite outcrop is visible on the lower slopes at the eastern end of the study area. A line of shell mounds is located on top of the outcrop (Figure 3).

\section{Approach and Methods}

Following Ambrose (1967), Stein (1992) lists four types of research questions that can be addressed through the study of shell mounds and adds one additional type:

- $\quad$ shellfish as a source of food;

- changes in ecological conditions over time inferred from species analysis;

- changes in the position of coastlines inferred from shell mound locations;

- cultural history inferred from the contents of shell mounds, such as artefacts; and

- the depositional and post-depositional processes that led to the formation of mounds.

While a great deal of attention has been paid to shell mounds in northern Australia, studies of the taphonomy of the mounds - Stein's fifth category - including studies specifically relating to the form, composition and age of the mounds, are limited (but see Bailey et al. 1994; Mitchell 1993). Here we make use of Stein's geoarchaeological approach to understanding mound formation, reflecting our interest in understanding the presence of shell mounds in relation to the coastal environmental fluctuations discussed above. We report on the preliminary study of four of the shell mounds at Wathayn, concentrating on three aspects that provide an indication of how the mounds have changed through time: the shape, size and aspect of the mounds, the composition of the mounds, and the history of mound formation.

Four shell mounds (WPSM66, WPSM75, WPSM76 and WPSM77; see Figure 3) were selected for the preliminary study from the Rio Tinto Alcan database of archaeological sites. They were chosen primarily because they were located at different distances from the current shoreline, and on different geomorphic units and substrates. WPSM66 is the most upslope mound, and is underlain by a hillslope soil/sediment. WPSM75 is located on the distal estuarine floodplain, closest to the river, and is underlain by estuarine mud. WPSM76 and WPSM77 are adjacent to each other on the lower slope and are underlain by sand, most likely comprising a former sandy beach or ridge. The characteristics of the substrates beneath each of the mounds were determined by standard sediment analysis techniques and results are shown in Table 1.

The size, shape and orientation of the mounds were recorded using terrestrial laser scanning (TLS). TLS allows rapid acquisition of large numbers of $\mathrm{x}, \mathrm{y}$ and $\mathrm{z}$ coordinates with subcentimetre accuracy without the need to impose an arbitrary grid across the object of interest. The technique is well-suited to modelling the surface of complex shapes (Rodríguez-Gonzálvez et al. 2012). A Leica Scanstation 2 was used to rapidly (5000 points per second) acquire very large numbers of points, termed a 'point cloud'. The point cloud was then post-processed, using Cyclone software, to both georeference the point clouds and to differentiate between the surface of the mound and objects such as tree trunks. The mound surfaces were described using a triangulated irregular network (TIN) from which attributes to describe the size, shape and orientation of the mound were derived. Other characteristics and features on the mound surfaces, such as vegetation, visible shell, hearths, surface sediments, stone artefacts and evidence of damage by animals such as pigs, were manually recorded into a database using data entry software on a small notebook computer.

To expose the interior structure of the mounds, a $1 \mathrm{~m}$ wide trench was excavated into the centre of each of the mounds along the shortest axis. This approach enabled us to excavate the smallest volume of material from the mound while at the same time exposing stratigraphic profiles in two directions, at the thickest part of the mound and from the centre to the outside. The mounds were excavated by hand, using mattocks and shovels. Excavated material was stockpiled and used to backfill the trench at the completion of profile recording and sampling. Excavation extended below the lowest shell layer to allow description and sampling of the substrate beneath the mounds. A robotic total station (RTS) was used to map the locations of the trenches and the collected samples. Stratigraphic units were identified based on 
changes in shell condition (whether complete or fragmented and the orientation of shells), changes in the texture and colour of the non-shell matrix, and the presence of mineral and plant inclusions.

Column samples were collected from the centre of each mound and analysed to determine species diversity and to measure post-depositional alteration of the mound structure. While Stein (1992) critiques the use of column samples, preferring samples from stratigraphically defined units, we chose to use column samples because they provided a means to analyse differences identified in the described stratigraphic section profiles as well as differences in shell composition that were not visible in the drawn stratigraphy. The samples were obtained by hand excavation at $10 \mathrm{~cm}$ intervals down the column, with $20 \mathrm{~cm} \times 20 \mathrm{~cm}$ squares being excavated in each case (i.e. approximately $4000 \mathrm{~cm}^{3}$ of material). All material - the matrix as well as the shell - was retained from these samples for later examination for other faunal remains (e.g. fish otoliths, marsupial bone). Just one column sample was collected from each of the four mounds examined for this pilot study. In subsequent work, multiple column samples from the length of the excavated trenches have been collected.

Shell fragmentation was measured following the techniques discussed by Muckle (1985) and Ford (1989). Fragmentation is a measure of trampling as well as compaction due to the presence of overburden, and was measured by particle size analysis. Shell samples were passed through five sieves with mesh sizes ranging from $8 \mathrm{~mm}$ through to $1 \mathrm{~mm}$, with the weight of the fraction retained in each of the sieves being recorded. Shell dissolution was measured following the procedures discussed by Hughes $(1980,1983)$ together with Muckle (1985) and Stein (1992). Shell dissolution is caused by the action of acidic water, either through ground water saturation or rain water percolation. Depending on the porosity of the deposit, these effects should be apparent throughout the mound. However, if shell mound formation was not continuous, it is expected that the degree of shell dissolution evident will vary, reflecting the existence of previously exposed surfaces that were subsequently buried. The presence of shell dissolution indicators was recorded macroscopically for every column sample from each of the four mounds and expressed as a percentage of shell within the column sample.

Species diversity was assessed on the basis of the presence and abundance of species using the ShannonWeiner species diversity index (a combination of species richness and evenness). Following Claassen (1998), changes in diversity can relate to regional and/or local environmental changes as well as shellfish collection strategies. However it is also worthwhile to investigate diversity differences among mounds dating to the same period.

Shell and charcoal samples for radiocarbon age determinations were collected from observable stratigraphic units within each mound, including the basal and uppermost shell layers. These samples were prepared and analysed at the Waikato Radiocarbon Dating Laboratory following standard radiometric and AMS radiocarbon protocols. The shells were washed in dilute hydrochloric acid $(\mathrm{HCl})$ to remove surface contamination and charcoal samples were treated with a series of dilute $\mathrm{HCl}$, sodium hydroxide $(\mathrm{NaOH})$ and $\mathrm{HCl}$ washes. All shells were tested for recrystallization (alteration of calcium carbonate $\left(\mathrm{CaCO}_{3}\right)$ from aragonite to calcite) prior to dating, and shells showing signs of alteration were rejected. Paired samples of shell and charcoal, which were used to assess the local marine reservoir correction value, were obtained from multiple locations within three of the mounds.

Samples for optically stimulated luminescence (OSL) dating were collected from the substrate immediately below the basal shell layer in each of the four mounds to provide a maximum age for the commencement of shell mound construction, as well as an indication of the age of the landforms on which the mounds are located. The samples were collected by hammering $40 \mathrm{~mm}$ diameter stainless steel tubes horizontally into the face of the trench approximately $10 \mathrm{~cm}$ below the unconformity separating the substrate from the mound. A portable gamma spectrometer was used to collect in situ background radiation data for the calculation of luminescence ages, and high resolution spectrometry was performed on bulk samples from around the tube collection sites. In the Luminescence Laboratory at Macquarie University, the first $2 \mathrm{~cm}$ of sediment from either end of each tube was discarded to eliminate all light exposed material. The remaining sediment was subjected to a $10 \% \mathrm{HCl}$ treatment to remove all carbonates followed by a $10 \%$ hydrogen peroxide $\left(\mathrm{H}_{2} \mathrm{O}_{2}\right)$ treatment to remove all organic matter. The sediment was then agitated in an ultrasonic bath to disaggregate resistant clay particles and wet-sieved at $63,90,125,180,212$ and $300 \mu \mathrm{m}$. The 90 $125,125-180$ and $180-212 \mu \mathrm{m}$ size fractions were isolated for further processing.

After being oven dried at $40^{\circ} \mathrm{C}$ for 24 hours, the material underwent a two-step density separation process using sodium polytungstate. Initially the heavy minerals were separated from the quartz and feldspar minerals at a density of $2.7 \mathrm{~g} / \mathrm{cm}^{3}$, then the feldspar minerals were separated from the quartz at a density of $2.62 \mathrm{~g} / \mathrm{cm}^{3}$. These samples were then sent to the University of Gloucester Geochronology Laboratory for analysis. Each sample required a 45 minute $40 \%$ hydrofluoric acid (HF) digestion followed by $10 \% \mathrm{HCl}$ treatment, dilution and dry resieve in this laboratory (Toms 2011). Given sufficient mass, each sample was mounted onto 18 aluminium discs as standard (8mm diameter), multigrain aliquots for dose recovery tests and De measurement. De values were quantified using a single-aliquot regenerative-dose (SAR) protocol (Murray and Wintle 2000, 2003) facilitated by a Risø TL-DA-15 irradiationstimulation-detection system (Markey et al. 1997; BøtterJensen et al. 1999).

Particle size analysis was conducted on separate bulk samples of all four substrate materials. Carbonates and organic matter were removed using $10 \% \mathrm{HCl}$ and $10 \%$ $\mathrm{H}_{2} \mathrm{O}_{2}$ treatments. The sediment was then agitated in an ultrasonic bath to disaggregate resistant clay particles and wet-sieved at $63,90,125,180,212$ and $300 \mu \mathrm{m}$. Samples were dried for 24 hours in a $40^{\circ} \mathrm{C}$ oven, weighed and reported as a percentage of the total mineral fraction. The moisture content of all samples was established by recording the wet (air-dried) sample weight, oven drying at $105^{\circ} \mathrm{C}$ for 24 hours, cooling in a desiccator and 
Table 2. Height, axial length, surface area and volume calculated for each mound using TLS data.

\begin{tabular}{|c|r|r|r|r|r|}
\hline Mound \# & Max. Height (m) & Long Axis (m) & Short Axis (m) & Volume $\left.\mathbf{( m}^{\mathbf{3}}\right)$ & Surface Area $\left(\mathbf{m}^{\mathbf{2}}\right)$ \\
\hline WPSM66 & 1.03 & 14.37 & 10.79 & 48.93 & 217.55 \\
\hline WPSM75 & 1.58 & 22.99 & 15.58 & 161.95 & 425.27 \\
\hline WPSM76 & 2.04 & 23.04 & 14.97 & 185.78 & 342.88 \\
\hline WPSM77 & 2.35 & 43.41 & 15.21 & 358.98 & 570.59 \\
\hline
\end{tabular}

Table 3. Measures of shell mound shape and orientation derived from TLS measurements.

\begin{tabular}{|c|c|c|r|r|r|r|}
\hline Mound \# & $\begin{array}{c}\text { S1 } \\
\text { (degrees) }\end{array}$ & $\begin{array}{c}\text { S2 } \\
\text { (degrees) }\end{array}$ & $\begin{array}{c}\text { Elongation } \\
\text { Ratio }\end{array}$ & $\begin{array}{c}\text { Surface Area/ } \\
\text { Volume Ratio }\end{array}$ & $\begin{array}{c}\text { Long Axis } \\
\text { Symmetry }\end{array}$ & $\begin{array}{c}\text { Short Axis } \\
\text { Symmetry }\end{array}$ \\
\hline WPSM66 & 6.09 & 5.86 & 0.75 & 4.45 & 1.68 & 1.39 \\
\hline WPSM75 & 9.17 & 7.28 & 0.68 & 2.63 & 2.23 & 0.59 \\
\hline WPSM76 & 13.00 & 12.00 & 0.65 & 1.85 & 1.41 & 1.11 \\
\hline WPSM77 & 15.77 & 7.31 & 0.35 & 1.59 & 1.01 & 1.09 \\
\hline
\end{tabular}

recording the oven dry weight. Sequential loss on ignition (LOI) at $550^{\circ} \mathrm{C}$ and $950^{\circ} \mathrm{C}$ provides an approximate measure of organic and carbonate content respectively. The material from soil moisture tests was used to establish organic content by igniting the oven dried samples in a Shimaden SR 5000 furnace at $550^{\circ} \mathrm{C}$ for 4 hours, cooling in a desiccator and recording the ignited soil weight. The sample was then returned to the furnace and ignited at $950^{\circ} \mathrm{C}$ for 15 minutes to establish the carbonate content. Sequential LOI was calculated using the following formulae, with results expressed as a relative percentage (Henri et al. 2001): LOI550 = $((\mathrm{DW} 105-\mathrm{DW} 550) / \mathrm{DW} 105)) * 100 ;$ LOI950 $=((\mathrm{DW} 550-$ DW950)/DW105))*100.

Shell Mound Morphology, Structure and Content at Wathayn

Shell Mound Size, Shape and Orientation

Size, shape and orientation data for the four mounds was obtained from the TLS data (Tables 2-3). Maximum height was measured between the highest and lowest points in the $\mathrm{z}$ axis value, while the long axis length was measured as the straight line length between the two most distant points on the lowest $\mathrm{x}, \mathrm{y}$ plane. The short axis was taken as the length between the most distant points at right angles to the long axis. Volume and surface area was measured relative to a best fit reference plane placed at the ground surface.

Shell mound shape (Table 3) was measured by calculating an elongation ratio (long axis length relative to short axis length) and a measure of the distribution of material (surface area divided by volume). Mound symmetry was also determined by calculating the volume of material either side of the long axis and expressing this as a ratio. Orientation was measured by deriving values for slope relative to the topographic location of the mounds. The parameter S1 is the slope (in degrees) of the mound surface facing downhill and perpendicular to the hillslope, while the parameter S2 is the slope of the mound surface parallel with the terrain slope.

An elongation ratio value of one occurs when the long and short axes are equal and the mound is approximately square or circular in plane section. WPSM66 is closest to this shape (Table 3, Figure 5). WPSM77 (Figure 6) is elongated compared to the other three mounds, and has the steepest S1 slope and the greatest difference in the slope measurements relative to the topographic position of the mounds. The three other mounds each have similar
S1 and S2 values, although WPSM66 is the flattest of the mounds (i.e. has the lowest slope values) while WPSM76 is the steepest. Steeper slopes on the mounds reduce the surface area relative to volume whereas shallower slopes increase surface area relative to volume. This relationship is expressed by dividing the surface area by the volume. WPSM66, with a value for this ratio of 4.45 , is a small mound that is also low and wide relative to its volume (Figure 5). In contrast, WPSM77 (Figure 6) with a surface area to volume ratio of 1.59 is a high, steep mound. WPSM77 is also relatively symmetrical, with low values for both the long and short axes symmetry ratios indicating that the mound is equally distributed along both of its axes (Table 3). In contrast, WPSM75 has quite different values for long and short axis symmetry indicating an asymmetric distribution of shells along both axes.

\section{Shell Mound Stratigraphy}

The stratigraphic profiles for the four mounds are illustrated in Figures 7-10 and the layers are described in Table 4. Mounds WPSM66, WPSM75 and WPSM77 exhibit a similar stratigraphy, at least down to the unconformity with the underlying substrate. The uppermost two or three layers in all three mounds are composed of fragmented shell with organically-rich matrices, including dense plant roots. The middle layers are comprised of shell that is much less fragmented, with abundant whole shell that appears to be cemented together. There are also lenses of ash. Shell in the basal layers is again fragmented. The matrix is dark brown in WPSM77 and grey in WPSM66 and WPSM75. Mound WPSM76 exhibits more complex stratigraphy (Figure 9), with some layers exhibiting limited lateral continuity.

\section{Shell Fragmentation}

The shell fragmentation for each of the four shell mounds are illustrated in Figures 11-14. In each case, the results indicate considerable variability in the proportions of shell fragments in each size fraction with depth, with the larger and smaller fractions alternating throughout the mounds. The alternation of the proportions of large and small shell fragments within the mounds suggests that multiple surfaces were exposed, and the shell fragmented, during the formation of the mounds. This pattern is more consistent with multiple periods of mound use interrupted by periods of mound abandonment than with continuous accumulation. 


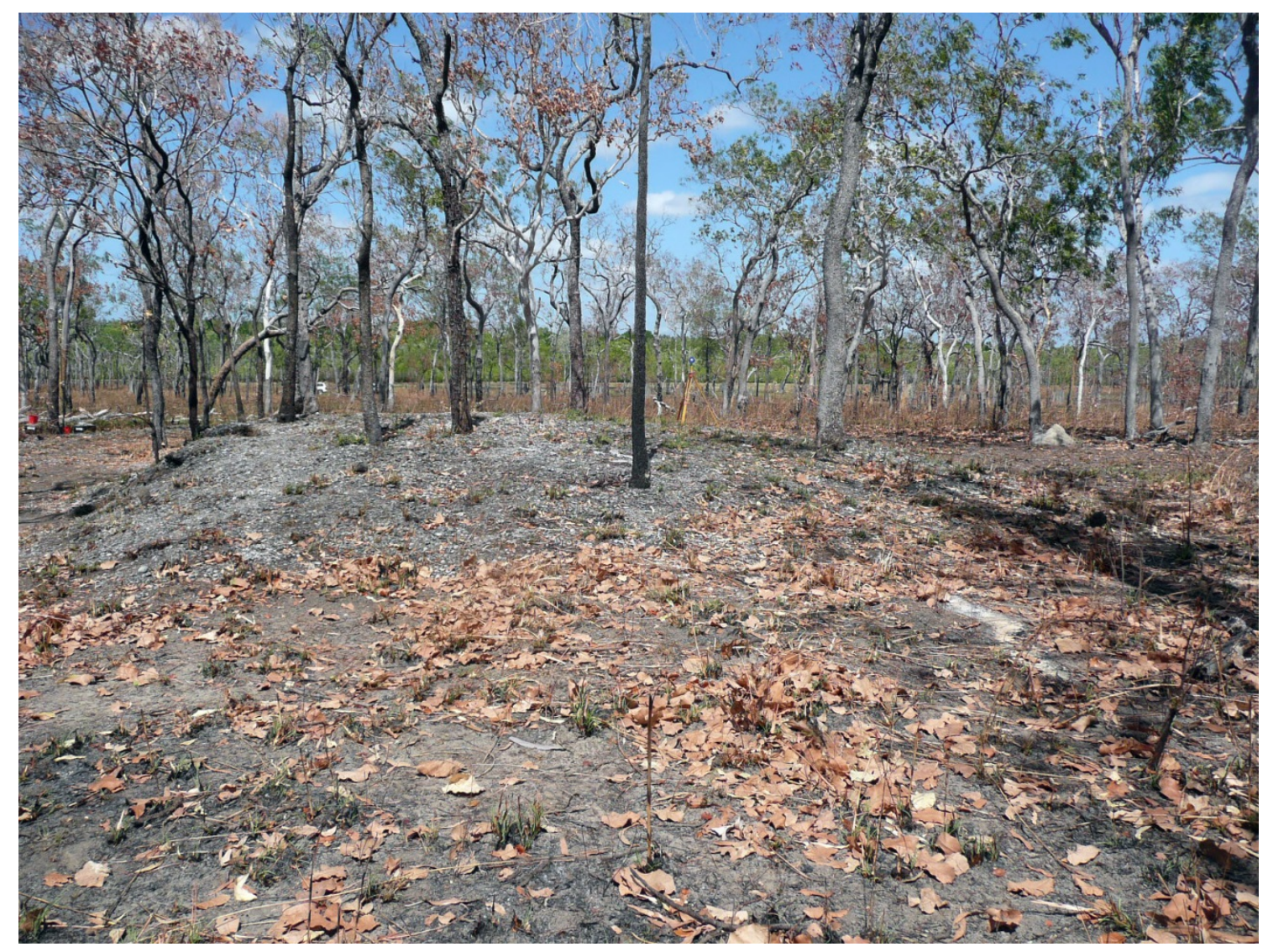

Figure 5. WPSM66.

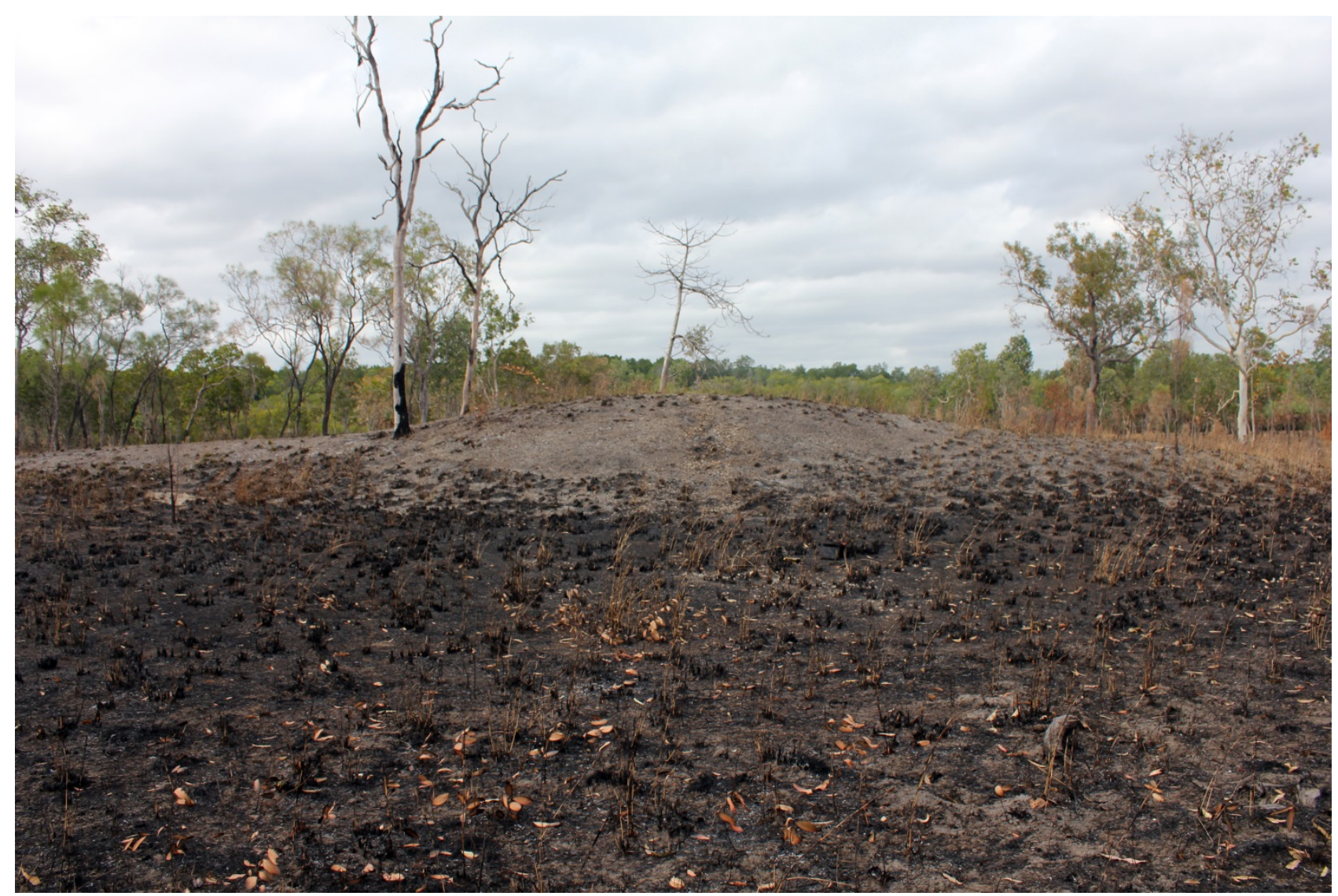

Figure 6. WPSM77. 

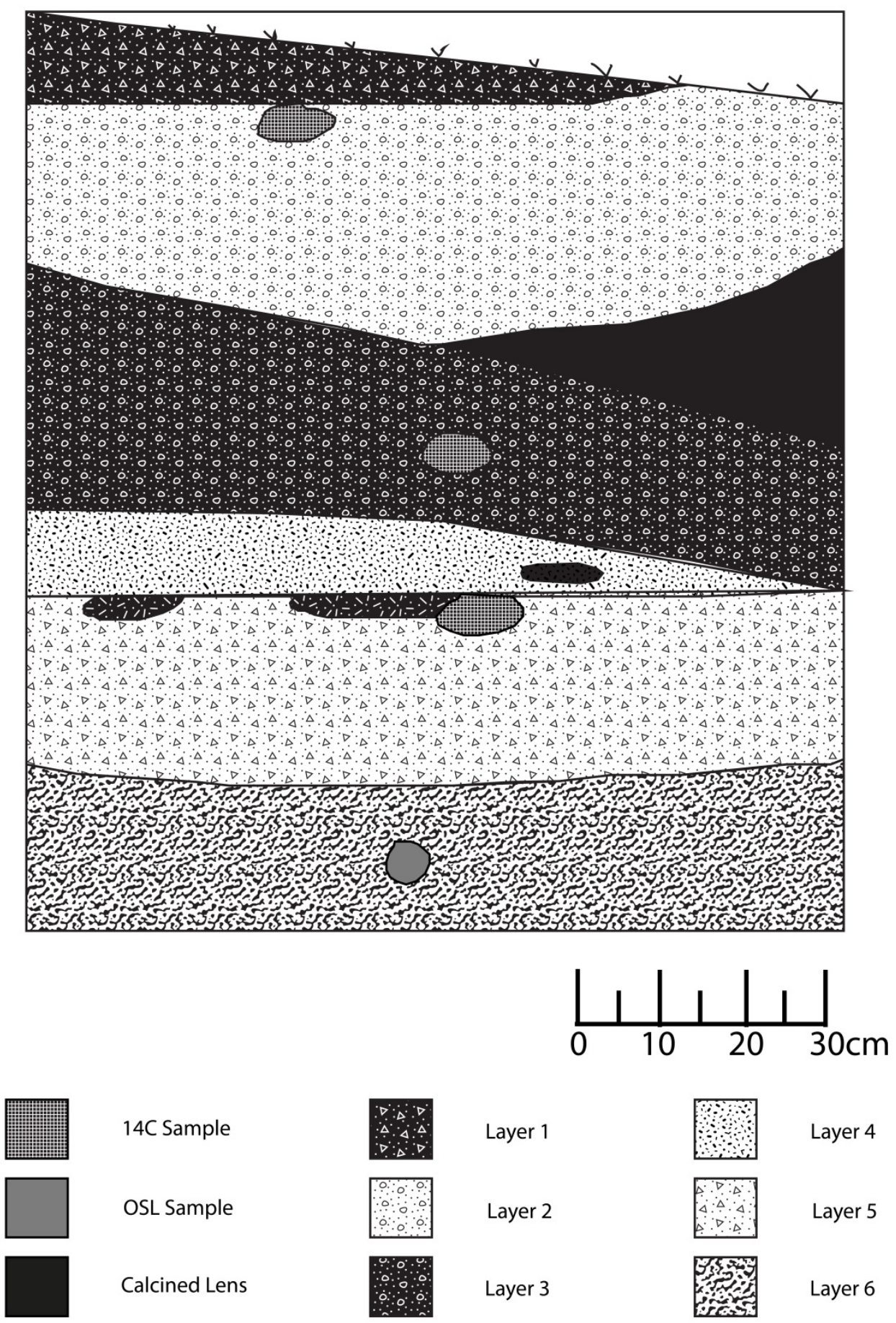

14C Sample

OSL Sample

Calcined Lens

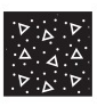

Layer 1
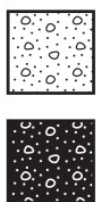

Layer 2

Layer 3

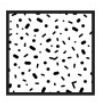

Layer 4

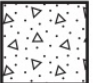

Layer 5

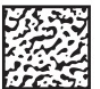

Layer 6

Figure 7. Stratigraphic diagram of WPSM66. 

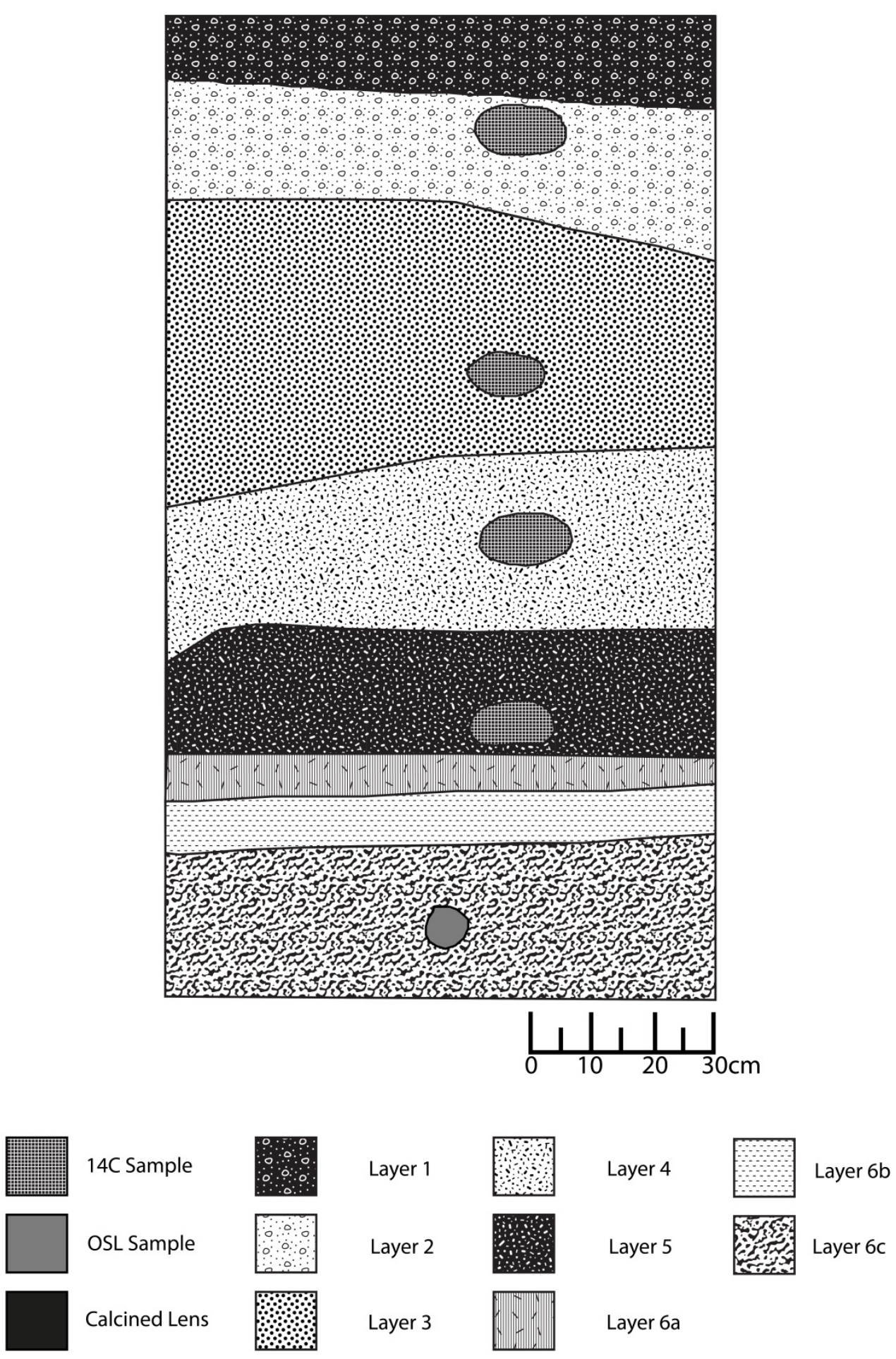

Figure 8. Stratigraphic diagram of WPSM75. 

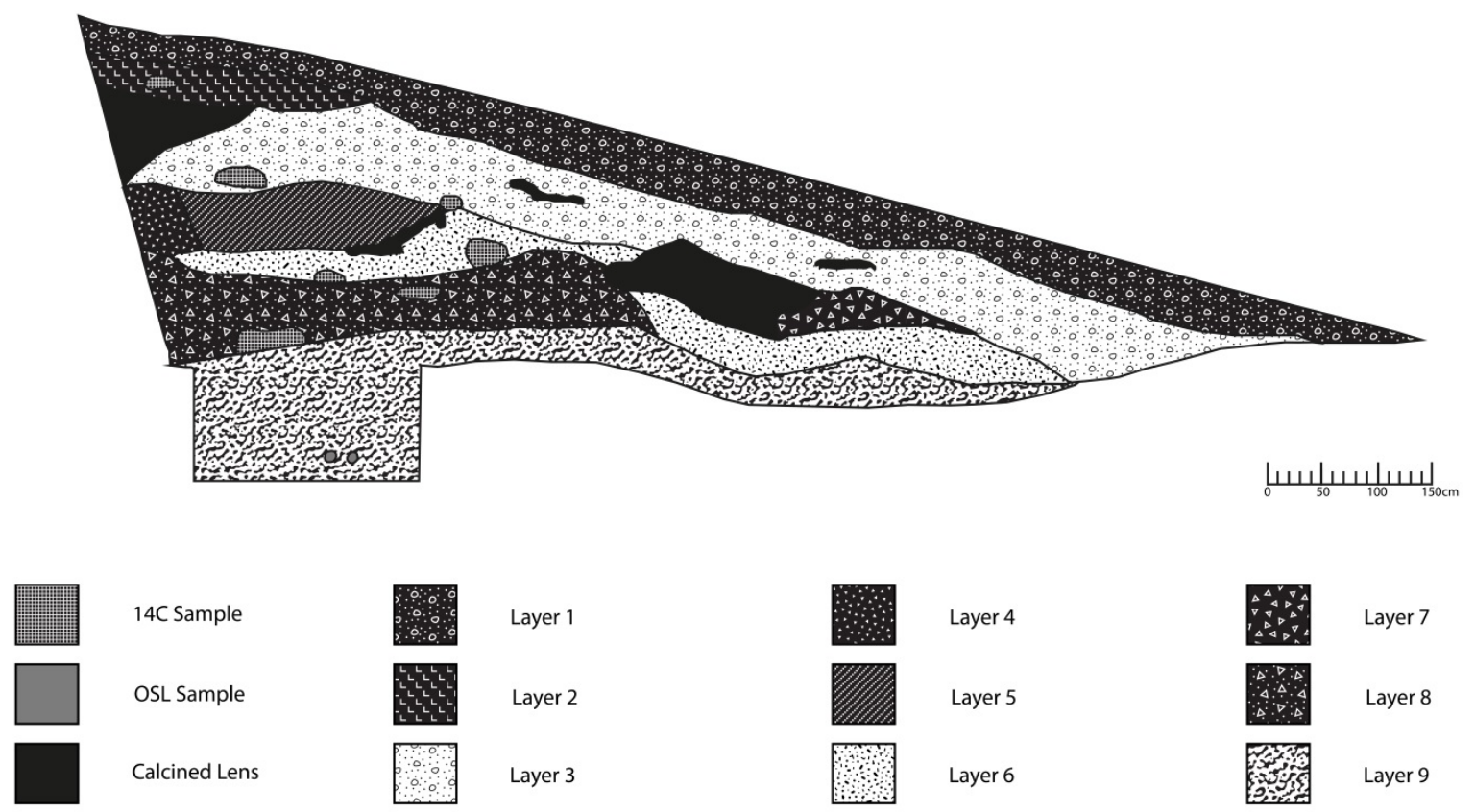

14C Sample
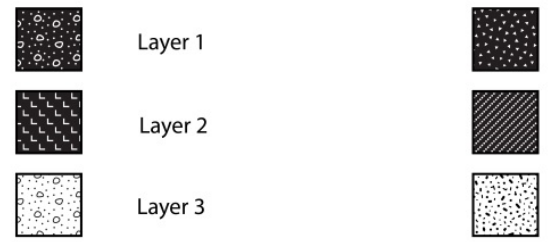

Layer 4

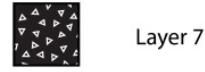

OSL Sample

Layer 5

$\begin{array}{lll}1 & \text { Layer } 8\end{array}$

Calcined Lens

Layer 3

Layer 6

Layer 9

Figure 9. Stratigraphic diagram of WPSM76. 


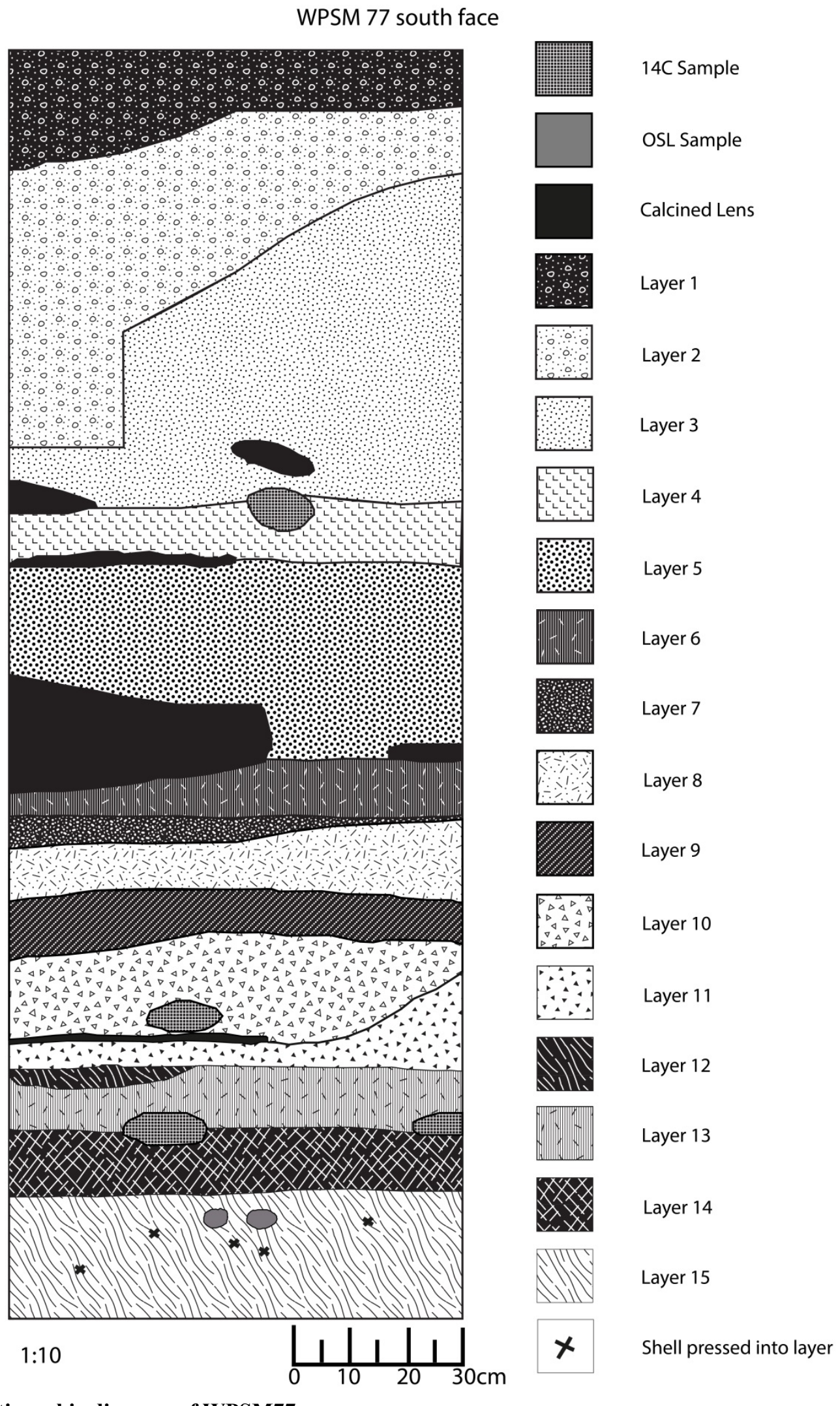

Figure 10. Stratigraphic diagram of WPSM77. 
Table 4. Stratigraphic descriptions of the mounds illustrated in Figures 7-10.

\begin{tabular}{|c|c|c|c|}
\hline Mound & Layer & Depth (cm) & Description \\
\hline \multirow{6}{*}{$\begin{array}{l}\text { WPSM66 } \\
\text { south face }\end{array}$} & 1 & $0-11$ & $\begin{array}{l}\text { Crushed shell with dark organic matrix ( } 7.5 \text { YR } 1.7 / 1-\text { black), abundant very fine to coarse } \\
\text { roots throughout. }\end{array}$ \\
\hline & 2 & $11-30$ & $\begin{array}{l}\text { Mostly whole shell in a lighter coloured organic-rich matrix ( } 7.5 \mathrm{YR} 3 / 3-\text { brownish black). } \\
\text { More ashy with charcoal specks, abundant very fine to coarse roots throughout. }\end{array}$ \\
\hline & 3 & $30-60$ & $\begin{array}{l}\text { Dense mostly whole shell, partially cemented; sparse ashy matrix. Clean shell appears } \\
\text { unburnt but shells are orangey-brown in colour. }\end{array}$ \\
\hline & 4 & $60-70$ & $\begin{array}{l}\text { Mostly whole Anadara with some Polymesoda in a matrix of crushed Anadara, ash and } \\
\text { charcoal; earthy matrix ( } 7.5 \mathrm{YR} 3 / 2 \text { - dark brown to } 7.5 \mathrm{YR} 6 / 1-\text { brownish grey); rare } \\
\text { medium to fine roots. }\end{array}$ \\
\hline & 5 & $70-90$ & $\begin{array}{l}\text { Less dense whole and broken shell in a loose ashy crushed shell matrix ( } 7.5 \text { YR 4/2 - } \\
\text { greyish brown); abrupt lower boundary. }\end{array}$ \\
\hline & 6 & $90+$ & $\begin{array}{l}\text { Hard, stony clay-dominated regolith; stones range from small pisoliths (2mm) to angular } \\
\text { fragments (up to } 2 \mathrm{~cm}) \text {; mottled yellowish brown }(10 \mathrm{YR} \mathrm{5/6)} \text { and dark brown }(10 \mathrm{YR} 3 / 3) \\
\text { with no indication of bleaching; rare fine roots. }\end{array}$ \\
\hline \multirow{7}{*}{$\begin{array}{l}\text { WPSM75 } \\
\text { south face }\end{array}$} & 1 & $0-15$ & $\begin{array}{l}\text { Thin layer of crushed shell and some whole shell in a dark organic matrix (10YR } 1.7 / 1- \\
\text { black) beneath compacted fragmented shell on surface; abundant very fine to medium roots; } \\
\text { gradual lower boundary. }\end{array}$ \\
\hline & 2 & $15-40$ & $\begin{array}{l}\text { Densely-packed whole shell in a lighter coloured earthy matrix (10.5YR } 2 / 3-\text { brownish } \\
\text { black); abundant fine roots; abrupt lower boundary. }\end{array}$ \\
\hline & 3 & $40-70$ & $\begin{array}{l}\text { Very densely-packed whole shell, with ashy matrix (7.5YR 5/2-greyish brown) filling } \\
\text { shells and voids; clear lower boundary. }\end{array}$ \\
\hline & 4 & $70-120$ & $\begin{array}{l}\text { As above but with more abundant matrix; very loose - does not hold vertical face, abrupt } \\
\text { lower boundary. }\end{array}$ \\
\hline & $5 \mathrm{a}$ & $120-125$ & $\begin{array}{l}\text { Crushed shell and abundant charcoal mixed into clay ( } 5 \text { Y } 3 / 2-\text { olive black, and white); } \\
\text { poorly-drained; clear lower boundary. }\end{array}$ \\
\hline & $5 \mathrm{~b}$ & $125-133$ & $\begin{array}{l}\text { Grey/gleyed (5Y 3/2) clay with infilled voids extending into layer 5c below; poorly drained; } \\
\text { gradual undulating lower boundary. }\end{array}$ \\
\hline & $5 c$ & $133+$ & $\begin{array}{l}\text { Stiff yellow (10YR } 5 / 8-\text { yellowish brown) mottled clay with rare gravel }(2.5 \mathrm{YR} 4 / 8-\text { red }) \text {; } \\
\text { poorly drained. }\end{array}$ \\
\hline \multirow{9}{*}{$\begin{array}{l}\text { WPSM76 } \\
\text { west face }\end{array}$} & 1 & $0-10$ & $\begin{array}{l}\text { Compacted fragmented shell surface; organic-rich topsoil with whole and fragmented shell } \\
\text { in an earthy matrix ( } 7.5 \mathrm{YR} 2 / 2 \text { - brownish black); abundant fine to medium roots; gradual } \\
\text { lower boundary. }\end{array}$ \\
\hline & 2 & $10-30$ & $\begin{array}{l}\text { Firm, greyish brown }(7.5 \mathrm{YR} 4 / 2) \text { silty fine sand containing mostly whole Anadara plus rare } \\
\text { fragments; few fine to medium roots. }\end{array}$ \\
\hline & 3 & $30-60$ & Whole Anadara shell in a dark organic matrix. \\
\hline & 4 & $60-90$ & Very fragmented shell with wind-blown sand feature. Grades laterally into Layer 5. \\
\hline & 5 & $90-110$ & Mixed fragmented and whole shell with scattered charcoal throughout. \\
\hline & 6 & $110-130$ & Whole unburnt Anadara shells in a dark organic matrix. \\
\hline & 7 & 130 & Lens of fragmented shell. \\
\hline & 8 & $130-150$ & $\begin{array}{l}\text { Dense calcined and fragmented shell with occasional whole Anadara shell; abrupt lower } \\
\text { boundary. }\end{array}$ \\
\hline & 9 & $150+$ & $\begin{array}{l}\text { Firm, poorly-sorted very fine to coarse sand; mottled brown }(7.5 \mathrm{YR} 4 / 3) \text { and reddish brown } \\
(5 \mathrm{YR} 4 / 6) \text {; fragmented shell mixed into the top } 2-4 \mathrm{~cm} \text {. }\end{array}$ \\
\hline \multirow{15}{*}{$\begin{array}{l}\text { WPSM77 } \\
\text { south face }\end{array}$} & 1 & $0-10$ & Very dark brown (7.5YR 2/3) organic-rich earthy matrix with whole Anadara shells. \\
\hline & 2 & $10-20$ & $\begin{array}{l}\text { Dark brownish black ( } 7.5 \mathrm{YR} 3 / 2) \text { organic-rich earthy matrix with more abundant whole } \\
\text { Anadara shell; fine roots at base. }\end{array}$ \\
\hline & 3 & $20-80$ & Clean, whole Anadara shell with greyish brown (7.5YR 4/2) silty fine sand matrix. \\
\hline & 4 & $80-90$ & Mostly whole Anadara shell but with some fragmented burnt shell. \\
\hline & 5 & $90-120$ & $\begin{array}{l}\text { Dark brown (7.5YR 3/3) silty fine sand matrix containing whole Anadara shell; burnt } \\
\text { patches of sediment. }\end{array}$ \\
\hline & 6 & $120-130$ & Charcoal and burnt/calcined whole Anadara shell. \\
\hline & 7 & $130-135$ & Calcined mostly whole Anadara shell with some fragmented shell. \\
\hline & 8 & $135-150$ & Whole Anadara shell with ash lenses in brown (7.5YR 4/3) sediment matrix. \\
\hline & 9 & $150-160$ & Burnt lenses with whole and fragmented burnt Anadara shell. \\
\hline & 10 & $160-175$ & Whole clean Anadara shell in silty fine sand matrix (7.5YR 3/2). \\
\hline & 11 & $175-180$ & Dense fragmented Anadara shell. \\
\hline & 12 & 180 & Polymesoda coaxans (mudshell) lens. \\
\hline & 13 & $180-190$ & Whole Anadara shell with a sandy matrix (7.5YR 5/8 - bright brown); abrupt boundary \\
\hline & 14 & $190-200$ & $\begin{array}{l}\text { Mottled (10R } 2 / 1 \text { - reddish brown and } 2.5 \mathrm{YR} 3 / 3 \text { - dark reddish brown) poorly-sorted very } \\
\text { fine to coarse sand; Anadara shells pressed into it. }\end{array}$ \\
\hline & 15 & $200+$ & $\begin{array}{l}\text { Mottled (10R } 2 / 1 \text { - reddish brown and } 2.5 \mathrm{YR} 3 / 3 \text { - dark reddish brown) poorly-sorted very } \\
\text { fine to coarse sand; moist. }\end{array}$ \\
\hline
\end{tabular}




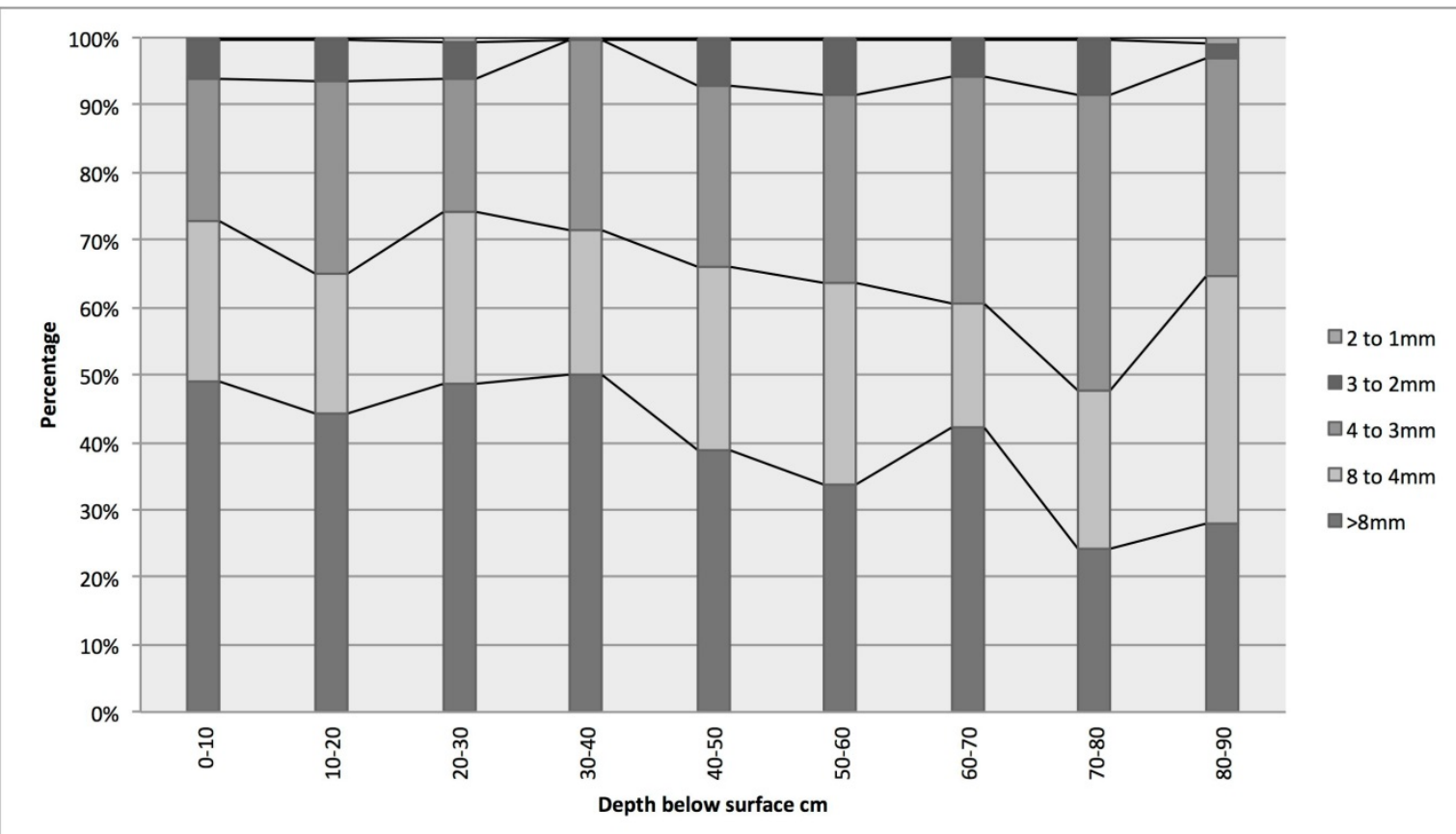

Figure 11. Shell fragment size variability with depth for WPSM66. Size divisions in $\mathrm{mm}$ are indicated by the differently-shaded segments of the bars, with the largest at the bottom and the smallest at the top.

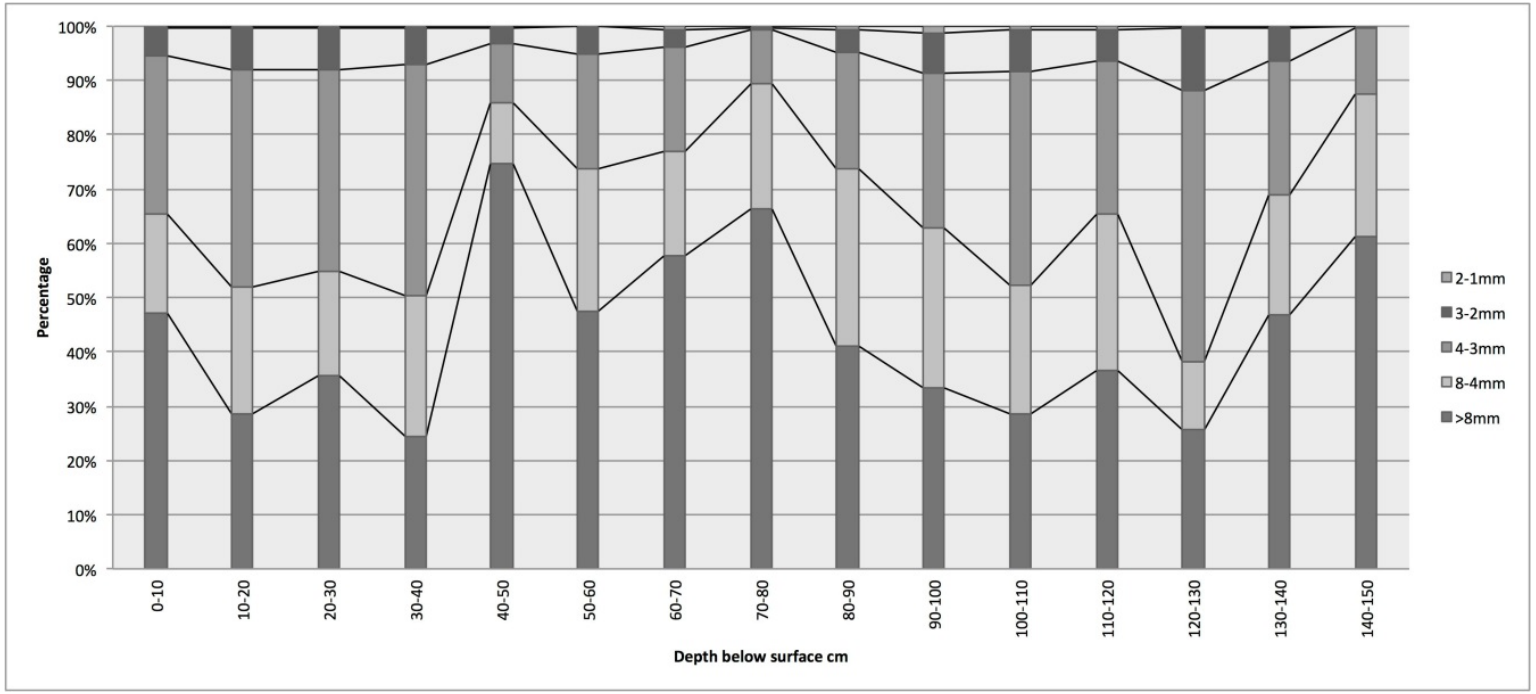

Figure 12. Shell fragment size variability with depth for WPSM75.

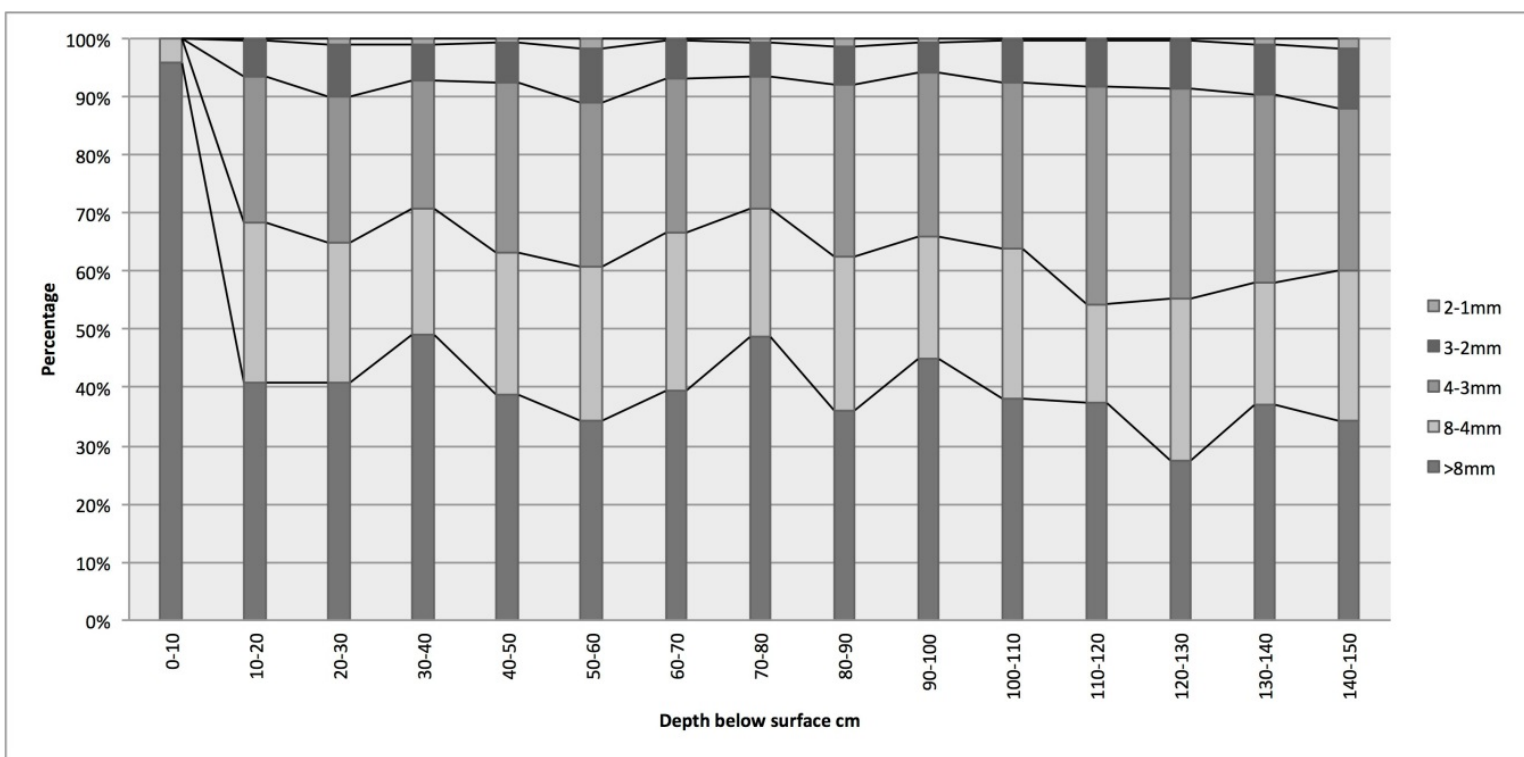

Figure 13. Shell fragment size variability with depth for WPSM76. 


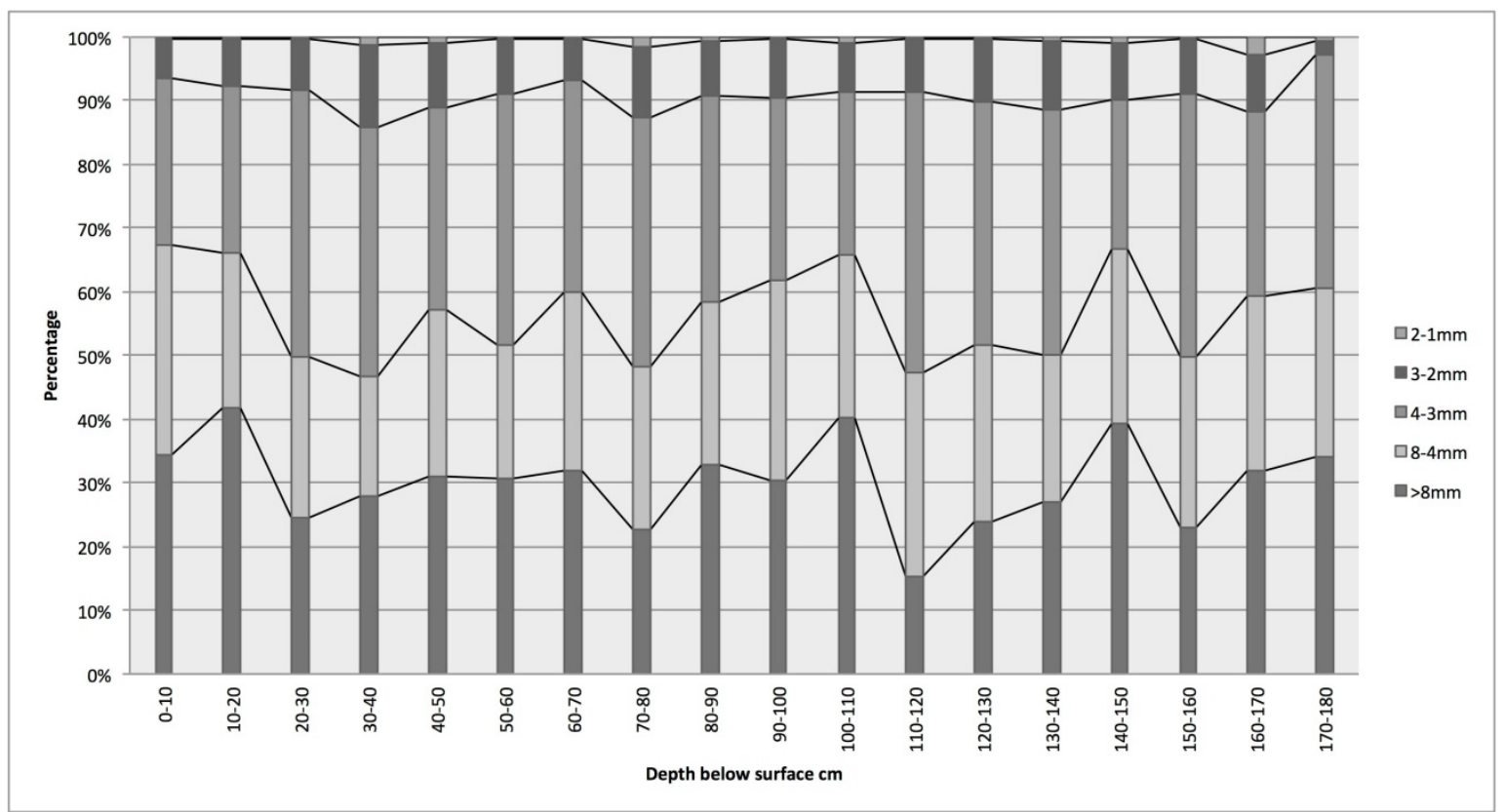

Figure 14. Shell fragment size variability with depth for WPSM77.

\section{Shell Dissolution}

Figures 15-18 show the proportions of shells within each mound with evidence for water dissolution. For WPSM66 the graph is tri-modal, with peaks in shell dissolution at the top of the column, at $40-50 \mathrm{~cm}$ depth and at the base of the column. The graph for WPSM75 is also tri-modal, although with a much smaller peak in the middle, at 60 $70 \mathrm{~cm}$. The plots for WPSM76 and 77 are multi-modal. Peaks in shell dissolution proportions in WPSM76 occur at $10-20 \mathrm{~cm}, 50-60 \mathrm{~cm}, 80-90 \mathrm{~cm}, 110-120 \mathrm{~cm}$ and at 130 $140 \mathrm{~cm}$; in WPSM 77 they occur at $0-10 \mathrm{~cm}, 40-50 \mathrm{~cm}, 80$ $90 \mathrm{~cm}, 120-130 \mathrm{~cm}, 140-150 \mathrm{~cm}$ and $160-170 \mathrm{~cm}$.

\section{Species Diversity}

The Shannon-Weiner diversity indices for each of the column samples obtained from the four mounds are shown in Figures 19-22. The values of the index vary from zero in cases where only a single species is present to a high of 0.74 (WPSM76, 80-90cm; Figure 21) where multiple species are present and frequencies of these species (i.e. evenness) are equally high. Values close to zero represent cases where a single species dominates. Results for the four mounds indicate variability in species diversity over the periods the mounds accumulated. WPSM66 indicates increased diversity at the top and bottom of the mound, with a smaller increase in the centre. The situation for mound WPSM75 is more complex, with high diversity at the surface of the mound, at $30-60 \mathrm{~cm}$ below the surface, and at $80-110 \mathrm{~cm}$ depth. The diversity increases again at the base of the deposit. The diversity index for WPSM76 is tri-modal with peaks at the top, centre and base of the mound. Finally, the plot of the index values for WPSM77 is multi-modal with peaks at the top of the deposit, $30-40 \mathrm{~cm}, 60-90 \mathrm{~cm}, 110$ $150 \mathrm{~cm}$ and again at the base of the deposit.

By calculating this diversity value in $10 \mathrm{~cm}$-thick samples, changes in species diversity over time can be quantified. Diversity values were calculated using number of identified specimen (NISP) counts to avoid issues with aggregation (Grayson 1984). NISP values by $10 \mathrm{~cm}$ level for each mound are presented in Table 5. Only seven species are recorded within the samples from these mounds, Anadara granosa (Linnaeus, 1758), Nerita lineata (Gmelin, 1791), Saccostrea cucullata (Born, 1778), Telescopium telescopium (Linnaeus, 1758), Marcia hiantina (Lamarck, 1818), Polymesoda (Geloina) coaxans (Gmelin, 1791) and Volema cochlidium (Linnaeus, 1758). Just three of these species, A. granosa, $P$. coaxans and $M$. hiantina, comprise the bulk of the shells in the sampled Wathayn shell mounds.

\section{Time Frames for Shell Mound Formation at Wathayn Radiocarbon Age Determinations}

Analyses of 'paired' charcoal/shell determinations from the same stratigraphic layers in three of the four mounds were undertaken to ascertain the local marine reservoir correction value $(\Delta R)$ for this region. All three $\Delta R$ results (Table 6) indicate enrichment in ${ }^{14} \mathrm{C}$ in the shells compared to the average global ocean as is often typical for estuarine shell species (Petchey et al. 2013). However, for archaeological $\Delta \mathrm{R}$, it is essential that the charcoal sampled comes from short-lived plants in contexts that are contemporaneous with the shell. Our pairs do not conform to these strict guidelines since all the charcoal samples were highly weathered and unable to be identified to short-lived species (R. Wallace, University of Auckland, pers. comm., 2011). Additional age in charcoal (i.e. inbuilt age which is the growth age of the tree) will reduce the difference between shell and charcoal ${ }^{14} \mathrm{C}$ determinations and the $\Delta \mathrm{R}$ value will be smaller and inaccurate. The values obtained for the shell mound samples analysed here are slightly smaller than results from four historic pre-1950 AD shells from the northwest Cape York Peninsula reported by Ulm et al. (in press) which returned a pooled $\Delta \mathrm{R}$ value of $-103 \pm 16{ }^{14} \mathrm{C}$ years.

Calendar ages for the shell samples were obtained using the Marine09 (Reimer et al. 2009) and OxCal software v.4.1.7 (Bronk Ramsey 2009) using a $\Delta \mathrm{R}$ value of $-103 \pm 16$ years (Ulm et al. in press). These results are shown in Table 7 . We have further evaluated the results using the OxCal 'sequence' and 'boundary' commands to determine approximate start and end dates for shell 


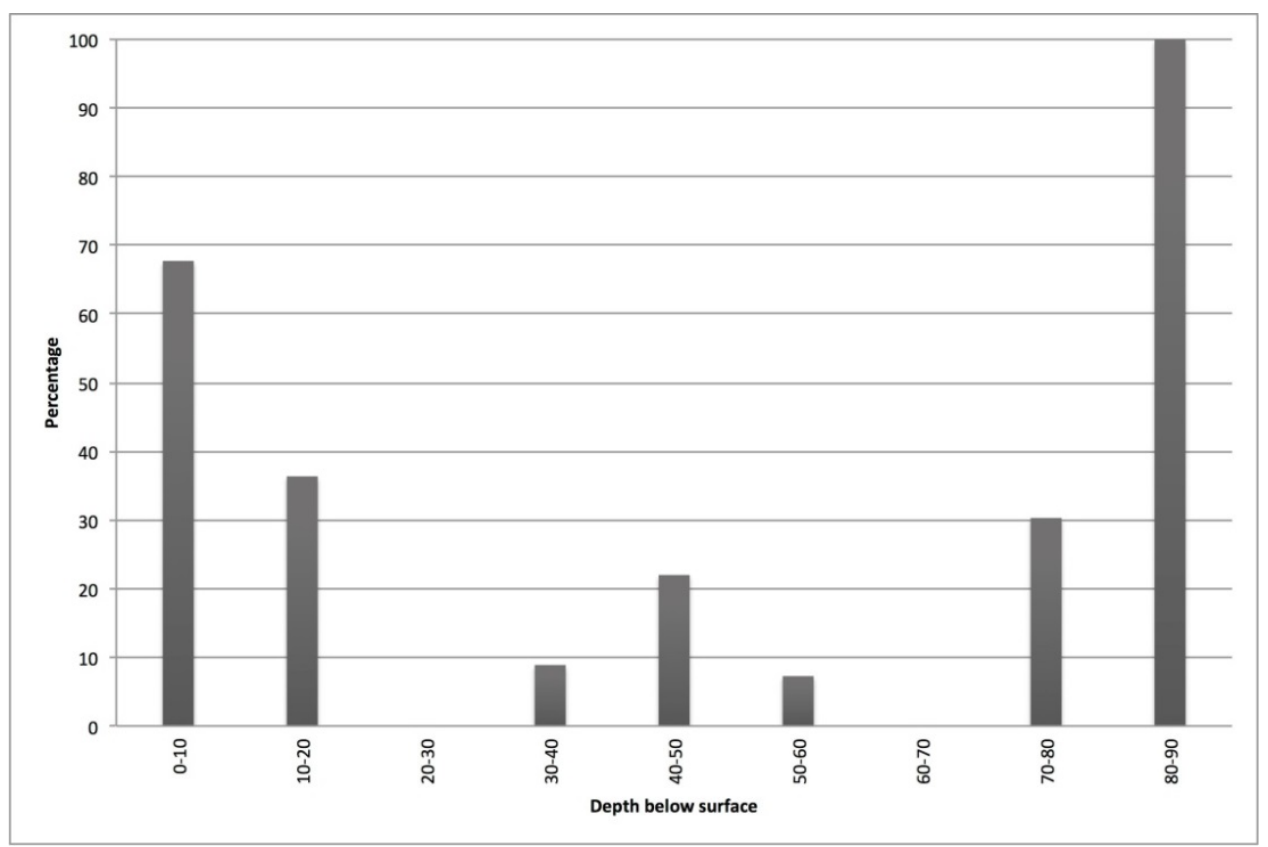

Figure 15. Shell dissolution variability with depth for WPSM66.

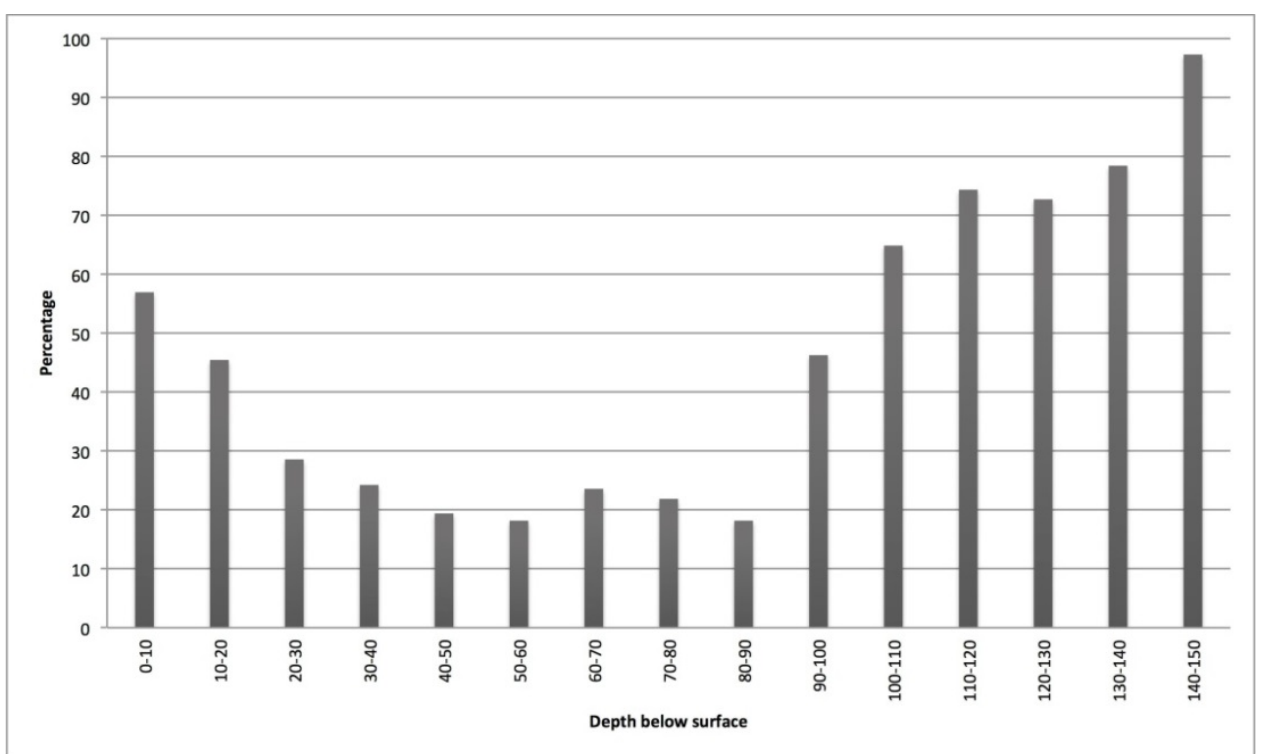

Figure 16. Shell dissolution variability with depth for WPSM75.

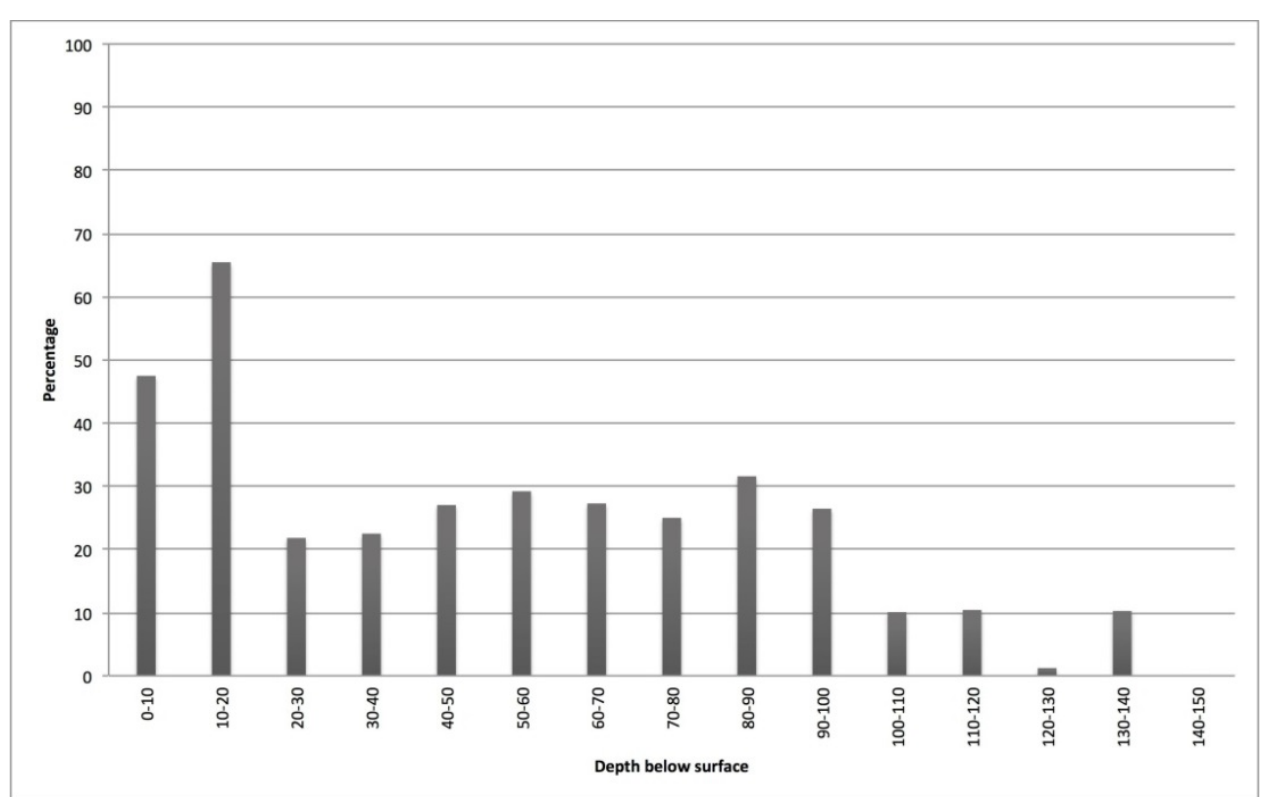

Figure 17. Shell dissolution variability with depth for WPSM76. 


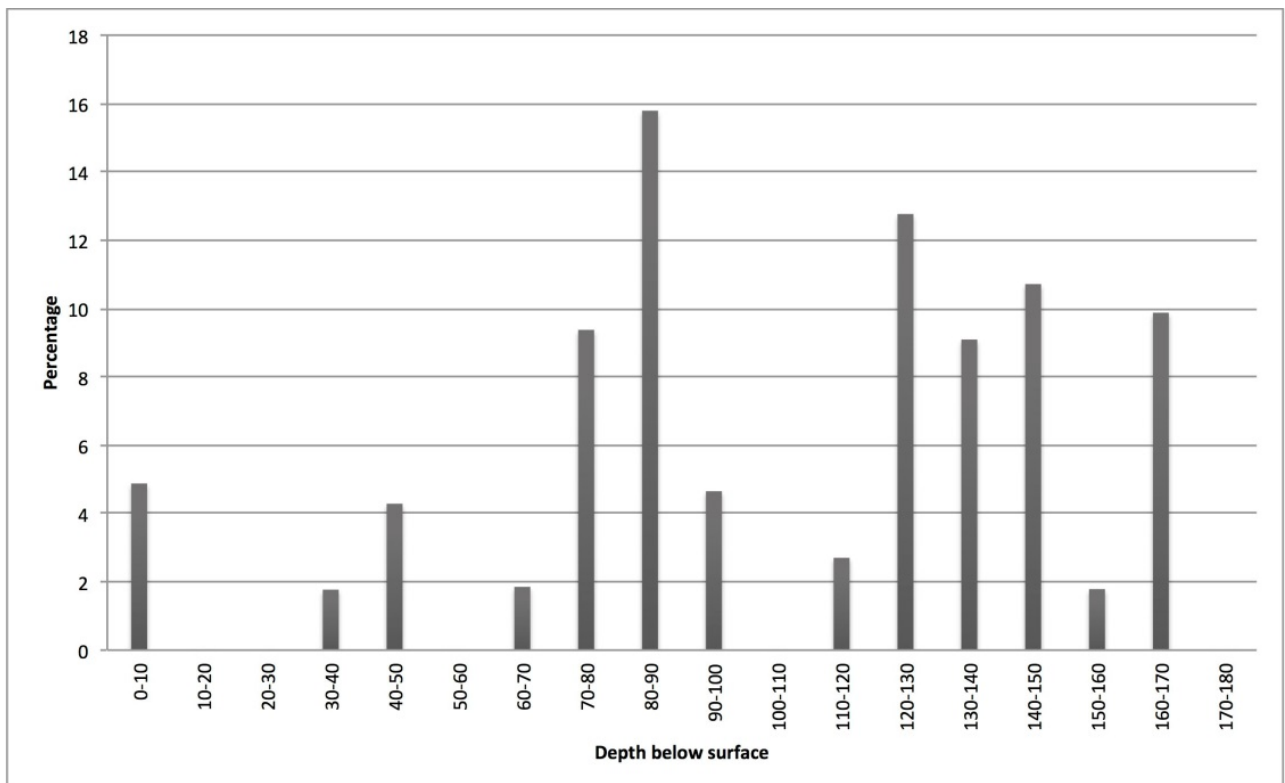

Figure 18. Shell dissolution variability with depth for WPSM77.

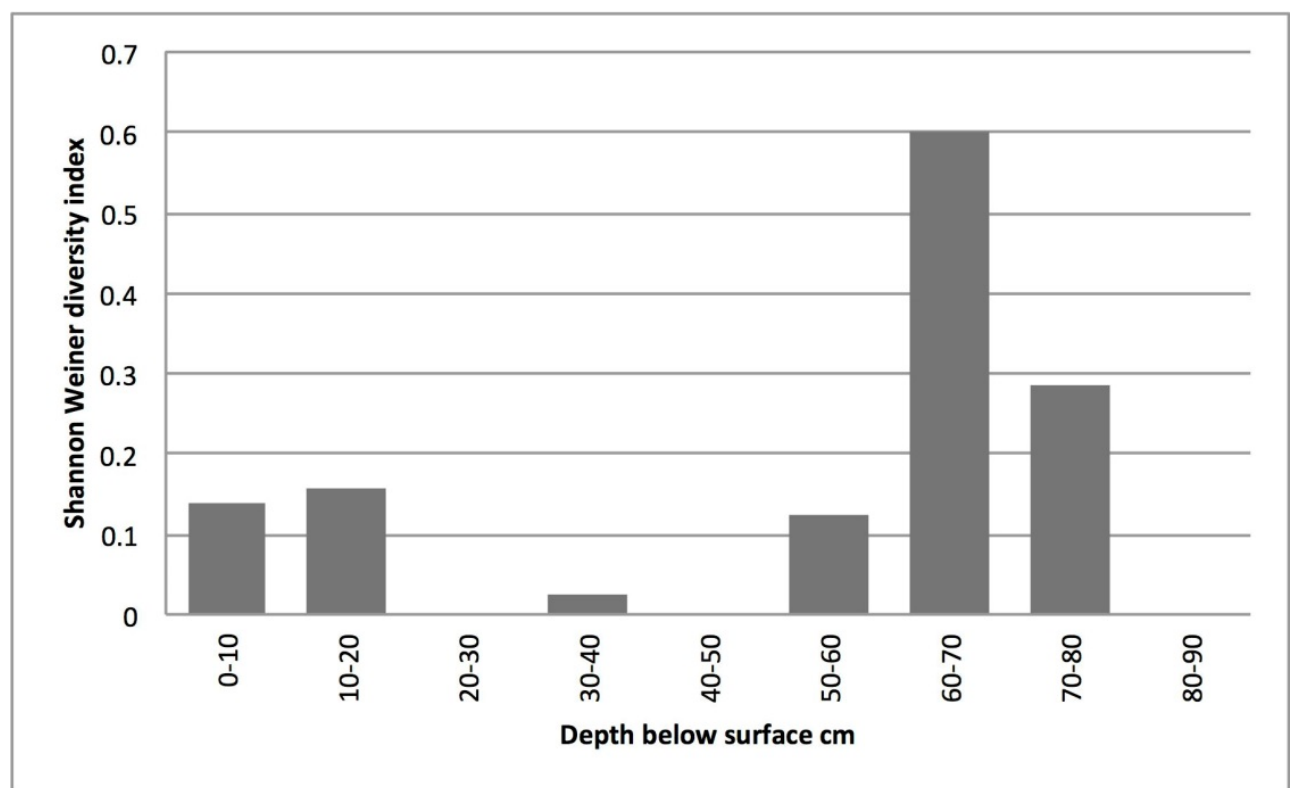

Figure 19. Shannon Weiner diversity index data for WPSM66. The higher the value of the index, the greater the species diversity.

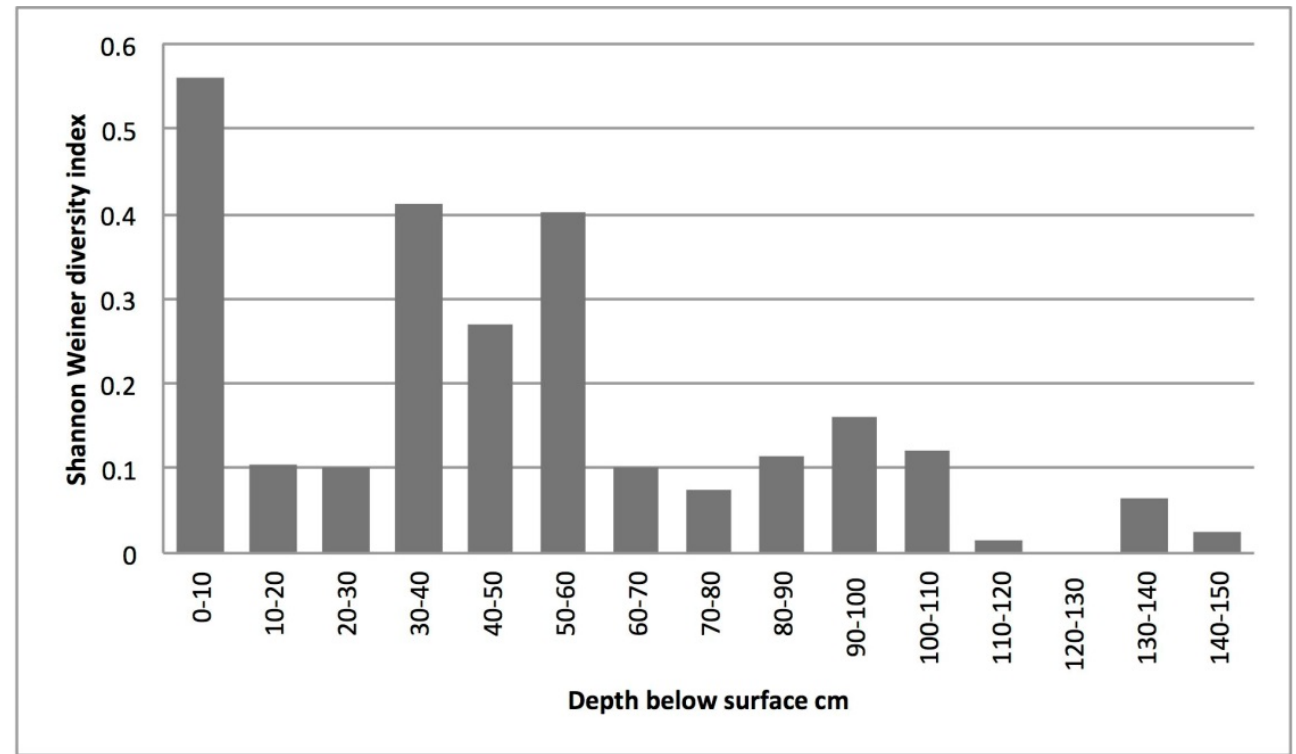

Figure 20. Shannon Weiner diversity index data for WPSM75.

Shiner et al.

q a r | Vol. 16 | 2013 | 83 


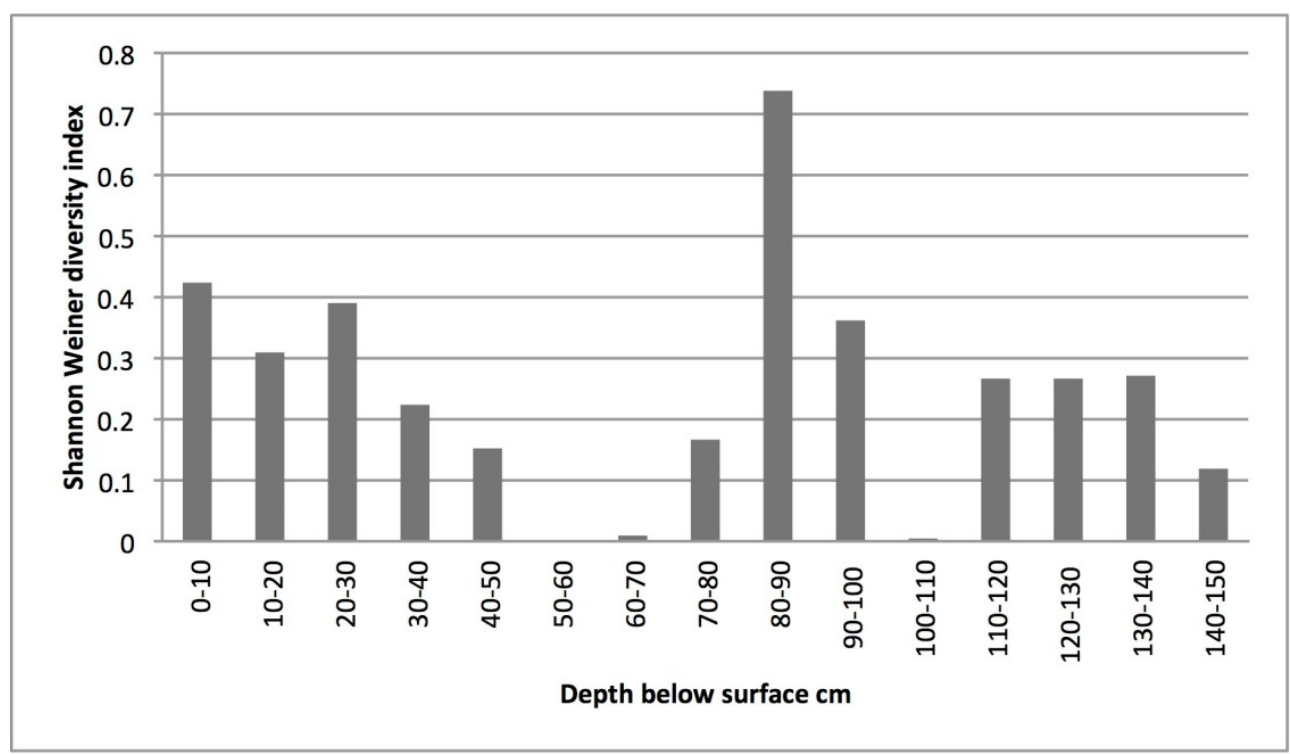

Figure 21. Shannon Weiner diversity index data for WPSM76.

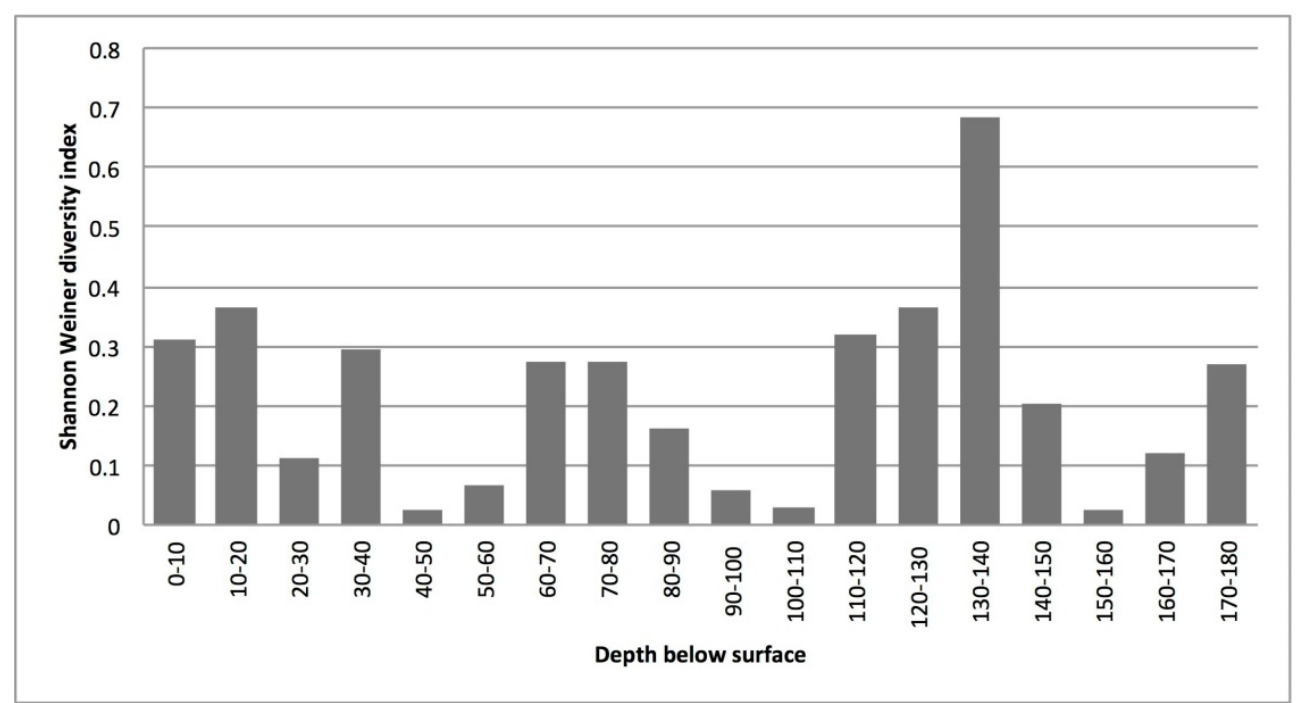

Figure 22. Shannon Weiner diversity index data for WPSM77. 
Table 5. Number of individual specimens (NISP) data for the four shell mounds.

\begin{tabular}{|c|c|c|c|c|c|c|c|c|}
\hline Mound \# & $\begin{array}{c}\text { Depth } \\
\text { (cm) }\end{array}$ & $\begin{array}{c}\text { Anadara } \\
\text { granosa }\end{array}$ & $\begin{array}{c}\text { Polymesoda } \\
\text { (Gelonia) } \\
\text { coaxans }\end{array}$ & $\begin{array}{c}\text { Saccostrea } \\
\text { cucullata }\end{array}$ & $\begin{array}{c}\text { Marcia } \\
\text { hiantina }\end{array}$ & $\begin{array}{l}\text { Telescopium } \\
\text { telescopium }\end{array}$ & $\begin{array}{c}\text { Volema } \\
\text { cochlidium }\end{array}$ & $\begin{array}{l}\text { Nerita } \\
\text { lineata }\end{array}$ \\
\hline \multirow{10}{*}{ WPSM66 } & $0-10$ & 505 & 16 & 0 & 0 & 0 & 0 & 0 \\
\hline & $10-20$ & 341 & 13 & 0 & 0 & 0 & 0 & 0 \\
\hline & $20-30$ & 463 & 0 & 0 & 0 & 0 & 0 & 0 \\
\hline & $30-40$ & 254 & 1 & 0 & 0 & 0 & 0 & 0 \\
\hline & $40-50$ & 285 & 0 & 0 & 0 & 0 & 0 & 0 \\
\hline & $50-60$ & 434 & 12 & 0 & 0 & 0 & 0 & 0 \\
\hline & $60-70$ & 630 & 174 & 12 & 0 & 0 & 0 & 1 \\
\hline & $70-80$ & 443 & 3 & 2 & 25 & 0 & 0 & 1 \\
\hline & $80-90$ & 274 & 0 & 0 & 0 & 0 & 0 & 0 \\
\hline & Total & 3629 & 219 & 14 & 25 & $\mathbf{0}$ & $\mathbf{0}$ & 2 \\
\hline \multirow{16}{*}{ WPSM75 } & $0-10$ & 469 & 119 & 0 & 0 & 7 & 0 & 0 \\
\hline & $10-20$ & 576 & 11 & 0 & 0 & 0 & 0 & 1 \\
\hline & $20-30$ & 549 & 8 & 0 & 0 & 1 & 0 & 1 \\
\hline & $30-40$ & 694 & 8 & 0 & 26 & 0 & 0 & 41 \\
\hline & $40-50$ & 303 & 14 & 0 & 0 & 0 & 0 & 6 \\
\hline & $50-60$ & 144 & 0 & 0 & 0 & 0 & 0 & 5 \\
\hline & $60-70$ & 216 & 0 & 0 & 0 & 0 & 1 & 3 \\
\hline & $70-80$ & 380 & 0 & 0 & 1 & 0 & 0 & 4 \\
\hline & $80-90$ & 395 & 5 & 1 & 0 & 0 & 0 & 2 \\
\hline & $90-100$ & 378 & 11 & 0 & 0 & 0 & 0 & 2 \\
\hline & $100-110$ & 439 & 10 & 0 & 0 & 1 & 0 & 0 \\
\hline & $110-120$ & 945 & 1 & 0 & 0 & 0 & 0 & 1 \\
\hline & $120-130$ & 317 & 0 & 0 & 0 & 0 & 0 & 0 \\
\hline & $130-140$ & 335 & 0 & 0 & 0 & 0 & 0 & 4 \\
\hline & $140-150$ & 270 & 0 & 1 & 0 & 0 & 0 & 0 \\
\hline & Total & 6410 & 187 & 2 & 27 & 9 & 1 & 70 \\
\hline \multirow{16}{*}{ WPSM76 } & $0-10$ & 114 & 20 & 0 & 0 & 0 & 0 & 0 \\
\hline & $10-20$ & 358 & 10 & 0 & 18 & 0 & 0 & 0 \\
\hline & $20-30$ & 236 & 32 & 0 & 0 & 1 & 0 & 0 \\
\hline & $30-40$ & 325 & 20 & 0 & 0 & 0 & 0 & 0 \\
\hline & $40-50$ & 218 & 8 & 0 & 0 & 0 & 0 & 0 \\
\hline & $50-60$ & 267 & 0 & 0 & 0 & 0 & 0 & 0 \\
\hline & $60-70$ & 690 & 1 & 0 & 0 & 0 & 0 & 0 \\
\hline & $70-80$ & 542 & 0 & 4 & 3 & 0 & 0 & 10 \\
\hline & $80-90$ & 514 & 108 & 0 & 60 & 2 & 0 & 0 \\
\hline & $90-100$ & 298 & 32 & 0 & 23 & 0 & 0 & 0 \\
\hline & $100-110$ & 483 & 0 & 0 & 3 & 0 & 0 & 0 \\
\hline & $110-120$ & 380 & 31 & 0 & 0 & 0 & 0 & 0 \\
\hline & $120-130$ & 196 & 0 & 0 & 16 & 0 & 0 & 0 \\
\hline & $130-140$ & 748 & 0 & 0 & 62 & 0 & 0 & 0 \\
\hline & $140-150$ & 528 & 14 & 0 & 0 & 0 & 0 & 0 \\
\hline & Total & 5897 & 276 & 4 & 185 & 3 & $\mathbf{0}$ & 10 \\
\hline \multirow{19}{*}{ WPSM77 } & $0-10$ & 464 & 40 & 0 & 0 & 3 & 0 & 0 \\
\hline & $10-20$ & 283 & 15 & 0 & 13 & 0 & 0 & 0 \\
\hline & $20-30$ & 664 & 15 & 0 & 0 & 0 & 0 & 5 \\
\hline & $30-40$ & 190 & 0 & 0 & 0 & 0 & 0 & 18 \\
\hline & $40-50$ & 489 & 0 & 0 & 2 & 0 & 0 & 0 \\
\hline & $50-60$ & 487 & 1 & 0 & 0 & 3 & 0 & 1 \\
\hline & $60-70$ & 500 & 5 & 0 & 23 & 0 & 0 & 4 \\
\hline & $70-80$ & 530 & 9 & 0 & 27 & 0 & 0 & 0 \\
\hline & $80-90$ & 431 & 0 & 0 & 17 & 0 & 0 & 0 \\
\hline & $90-100$ & 664 & 7 & 0 & 0 & 0 & 0 & 0 \\
\hline & $100-110$ & 502 & 1 & 0 & 1 & 0 & 0 & 0 \\
\hline & $110-120$ & 84 & 9 & 0 & 0 & 0 & 0 & 0 \\
\hline & $120-130$ & 364 & 0 & 0 & 45 & 0 & 0 & 1 \\
\hline & $130-140$ & 233 & 0 & 0 & 311 & 0 & 0 & 0 \\
\hline & $140-150$ & 378 & 1 & 0 & 18 & 0 & 0 & 0 \\
\hline & $150-160$ & 490 & 2 & 0 & 0 & 0 & 0 & 0 \\
\hline & $160-170$ & 303 & 31 & 3 & 0 & 0 & 0 & 0 \\
\hline & $170-180$ & 245 & 0 & 0 & 0 & 0 & 0 & 0 \\
\hline & Total & 7301 & 136 & 3 & 457 & 6 & $\mathbf{0}$ & 29 \\
\hline
\end{tabular}


Table 6. ${ }^{14} \mathrm{C}$ age determinations on paired charcoal/shell samples from three of the four mounds to determine the local marine reservoir correction value $(\Delta R)$. An estimate of the atmospheric calibration curve error (IntCal09: Reimer et al. 2009) over the $1 \sigma$ span of the radiocarbon age was used to derive the calculated marine modeled age $[\operatorname{Rg}(t)]$ error, whereby, atmospheric age $\sigma=\sqrt{ }\left(\sigma^{14} \mathrm{C}\right.$ age $^{2}+$ average of calibration curve error $\left.{ }^{2}\right)$. The $\Delta R$ standard error is calculated by the formula $\Delta R \sigma=\sqrt{ }\left(\sigma \operatorname{Rg}(t)^{2}+\sigma \operatorname{Rs}(t)^{2}\right) . *=\mathbf{A M S}$.

\begin{tabular}{|c|c|c|c|c|c|c|}
\hline Mound \# & $\begin{array}{l}\text { Depth } \\
\text { (cm) }\end{array}$ & Sample Material & $\begin{array}{c}{ }^{14} \mathrm{C} \text { age (BP) } \\
{[\operatorname{Rs}(\mathrm{t})]}\end{array}$ & $\begin{array}{c}\text { Marine } \\
\text { Modelled Age } \\
{[\operatorname{Rg}(t)]} \\
\end{array}$ & $\begin{array}{c}\Delta R(\text { years) } \\
{[\operatorname{Rs}(t)-\operatorname{Rg}(t)]}\end{array}$ & Lab. No. \\
\hline \multirow[t]{2}{*}{ WPSM75 } & 135 & Charcoal & $1625 \pm 25$ & $1980 \pm 19$ & $-156 \pm 42$ & Wk-28977* \\
\hline & 125 & Anadara granosa & $1824 \pm 37$ & - & & Wk-28976 \\
\hline \multirow[t]{2}{*}{ WPSM76 } & 160 & Charcoal & $2445 \pm 25$ & $2791 \pm 81$ & $-98 \pm 90$ & Wk-28985* \\
\hline & 145 & Anadara granosa & $2693 \pm 39$ & - & & Wk-28984 \\
\hline \multirow[t]{2}{*}{ WPSM 77} & 190 & Charcoal & $2550 \pm 25$ & $2948 \pm 27$ & $-176 \pm 46$ & Wk-28992* \\
\hline & 185 & Anadara granosa & $2772 \pm 37$ & - & & Wk-28991 \\
\hline$\Delta \mathrm{R}$ Average & & & & & $-158 \pm 29$ & \\
\hline
\end{tabular}

Table 7. ${ }^{14} \mathrm{C}$ age determinations on Anadara granosa shells collected from within the four shell mounds at Wathayn. All marine shell samples were corrected using a local $\Delta R$ of $-103 \pm 16$ (Ulm et al. in press).

\begin{tabular}{|c|c|c|c|c|c|c|}
\hline Mound \# & $\begin{array}{l}\text { Depth } \\
\text { (cm) }\end{array}$ & Lab. No. & $\begin{array}{l}\delta^{13} \mathrm{C} \\
(\% \mathrm{o})\end{array}$ & $\begin{array}{c}{ }^{14} \mathrm{C} \text { Age } \\
\text { (years BP) }\end{array}$ & $\begin{array}{c}\text { Calibrated Age BP } \\
(68.2 \% \text { prob. })\end{array}$ & $\begin{array}{c}\text { Median Age } \\
\text { (cal BP) }\end{array}$ \\
\hline \multirow{3}{*}{ WPSM66 } & 90 & Wk-28972 & $-2.5 \pm 0.2$ & $2726 \pm 39$ & $2680-2520$ & 2585 \\
\hline & 70 & Wk-28970 & $-2.1 \pm 0.2$ & $2684 \pm 29$ & $\begin{array}{l}2645-2630 \\
2610-2450\end{array}$ & 2530 \\
\hline & 20 & Wk-28969 & $-2 \pm 0.2$ & $2590 \pm 39$ & $2445-2325$ & 2390 \\
\hline \multirow{4}{*}{ WPSM75 } & 125 & Wk-28976 & $-2.2 \pm 0.2$ & $1824 \pm 37$ & $1525-1410$ & 1470 \\
\hline & 85 & Wk-28975 & $-2.6 \pm 0.2$ & $1884 \pm 29$ & $1600-1500$ & 1545 \\
\hline & 60 & Wk-28974 & $-2.7 \pm 0.2$ & $1800 \pm 28$ & $1500-1400$ & 1445 \\
\hline & 25 & Wk-28973 & $-3.3 \pm 0.2$ & $1359 \pm 37$ & $1055-950$ & 1005 \\
\hline \multirow{3}{*}{ WPSM76 } & 145 & Wk-28984 & $-2.2 \pm 0.2$ & $2693 \pm 39$ & $\begin{array}{l}2650-2620 \\
2615-2465\end{array}$ & 2545 \\
\hline & 45 & Wk-28979 & $-2.4 \pm 0.2$ & $2607 \pm 33$ & $2445-2335$ & 2405 \\
\hline & 18 & Wk-28978 & $-3.2 \pm 0.2$ & $2485 \pm 38$ & $2325-2205$ & 2260 \\
\hline \multirow{3}{*}{ WPSM77 } & 185 & Wk-28991 & $-2.1 \pm 0.2$ & $2772 \pm 37$ & $2725-2595$ & 2650 \\
\hline & 160 & Wk-28990 & $-1.9 \pm 0.2$ & $2708 \pm 37$ & $2660-2495$ & 2565 \\
\hline & 85 & Wk-28988 & $-2.4 \pm 0.2$ & $2659 \pm 35$ & $2570-2380$ & 2485 \\
\hline
\end{tabular}

Table 8. Age estimates for start, end and span of shell accumulation in the Wathayn mounds, based on shell radiocarbon age determinations. The wide ranges for the start and end boundaries are indicative of the small number of determinations and the lack of constraints for the end of each sequence. Quoted values vary by run.

\begin{tabular}{|c|c|c|c|c|}
\hline Mound \# & $\begin{array}{l}\text { Start (cal. BP) } \\
(68.2 \% \text { prob.) }\end{array}$ & $\begin{array}{l}\text { End (cal. BP) } \\
(68.2 \% \text { prob.) }\end{array}$ & $\begin{array}{c}\text { Span (years) } \\
(68.2 \% \text { prob.) }\end{array}$ & Comments \\
\hline WPSM77 & $2745-2514$ & $2475-2271$ & $67-451$ & \\
\hline WPSM66 & $2750-2455$ & $2456-2195$ & $9-513$ & \\
\hline WPSM76 & $2676-2355$ & $\begin{array}{l}2365-2356 \\
2327-2051\end{array}$ & $103-662$ & \\
\hline WPSM75 & $1738-1466$ & $1045-750$ & $483-991$ & 300 year hiatus between 1100 and 1400 cal BP \\
\hline
\end{tabular}

Table 9. OSL age data of Wathayn mound substrate samples. Uncertainties in age are quoted at $1 \sigma$ confidence, are based on analytical errors, and reflect combined systematic and experimental variability and (in parenthesis) experimental variability alone.

\begin{tabular}{|c|c|c|c|c|}
\hline Mound \# & $\begin{array}{c}\text { Overburden Depth } \\
(\mathbf{m})\end{array}$ & $\begin{array}{c}\text { Mean Equivalent Dose } \\
\text { De (Gy) }\end{array}$ & $\begin{array}{c}\text { Total Dose Rate Dr } \\
\mathbf{( G y . k a}^{-1} \mathbf{)}\end{array}$ & $\begin{array}{c}\text { Age } \\
(\mathbf{k a})\end{array}$ \\
\hline WPSM66 & 1.01 & $5.38 \pm 0.45$ & $1.37 \pm 0.09$ & $3.9 \pm 0.4(0.3)$ \\
\hline WPSM75 & 1.56 & $17.66 \pm 2.26$ & $3.00 \pm 0.25$ & $5.9 \pm 0.9(0.7)$ \\
\hline WPSM76 & 1.57 & $3.33 \pm 0.15$ & $0.75 \pm 0.08$ & $4.4 \pm 0.5(0.2)$ \\
\hline WPSM77 & 2.06 & $3.38 \pm 0.15$ & $0.66 \pm 0.07$ & $5.1 \pm 0.6(0.2)$ \\
\hline
\end{tabular}


accumulation episodes for each mound (Table 8). These commands place constraints on the calibrated ages based on stratigraphic context (i.e. layer A must be younger than layer B which must be younger than layer $\mathrm{C}$ ) and provide approximate start and end dates for each mound as well as span of mound construction (results reported at $68.2 \%$ ).

The approximate start and end dates for shell accumulation in mounds WPSM66, 76 and 77 are similar, with deposition of shells commencing about 2750 cal BP and ceasing before about 2050 cal BP. Accumulation, as indicated by the span data, appears to be relatively rapid with no clear hiatus in shell accumulation in any of these mounds. Shell accumulation in WPSM75, on the other hand, began much more recently, around $1750 \mathrm{cal} \mathrm{BP}$, and ceased around $750 \mathrm{cal}$ BP. There is also the suggestion that two periods of accumulation, separated by a hiatus of approximately 300 years between 1100 and $1400 \mathrm{cal}$ BP, may be represented in this mound.

\section{OSL Age Determinations}

The results of the optically stimulated luminescence (OSL) age determinations on sediment samples from beneath each of the four mounds are shown in Table 9 and the physical characteristics of the sediments are shown in Table 1. WPSM66, located in a mid-slope position on the hillslope leading down from the bauxite plateau, is underlain by gravelly substrate with a matrix comprising roughly equal proportions of sand and silt/clay. The OSL age estimate of 4300-3500 BP most likely is a function of the high turnover rate of the regolith by bioturbation in this region (Eggleton and Taylor 2008). WPSM75, located at the junction between the estuarine floodplain and the hillslope, is underlain by dominantly clay-sized substrate with high organic and moisture contents. The OSL age estimate of $6800-5000 \mathrm{BP}$ is consistent with a model of fine-grained estuarine infilling following post-glacial marine transgression. WPSM76 and 77 are located adjacent to each other in a lower slope position. The substrate is coarse sandy material with low organic and carbonate content, suggestive of a beach or beach ridge. The OSL age determinations of 4900-3900 $\mathrm{BP}$ and 5700-4500 BP, slightly younger than that for the distal estuarine floodplain under WPSM75, suggest that there may have been a hiatus in shoreline progradation at this time, with relatively coarse sandy sediments being deposited on the estuary shore and perhaps reworked into a linear ridge parallel to the shore.

\section{Discussion}

Our project aims to understand, at a local level, how Aboriginal people dealt with changes in the environment generated as an outcome of global and regional, long- and short-term environmental shifts. Previous studies in northern Australia have linked changes in the use of coastal resources to significant regional and global environmental changes, sometimes linked to climate change (e.g. O'Connor 1999; Bourke et al. 2007). However, while the environment certainly did shift in significant ways in the past, understanding the link between these changes, how people responded, the types of archaeological records produced by these actions, and the present-day form of these records has not always been a focus of study.
Rather than emphasise uniformity, we began our project with an interest in spatial and temporal variability in human response to environmental change. Our review of the palaeoenvironmental literature indicates that while there are general trends in environmental change through time, actual sequences of change vary regionally. Thus, while geomorphological records of sea-level change demonstrate a reduction in variability to within $1 \mathrm{~m}$ in the last c. 1000 years, the trajectory of sea-level fall does not appear to be uniform across the region. Similarly, the chronology of hydrological variability constructed from palynological proxy data indicates a general trend of increasing wetness with an increase in climatic fluctuation towards the present, although regions retain a different record of precipitation effectiveness. Sedimentation processes are closely associated with the effects of sealevel change and hydrological processes. However, the formation of beach ridges and infilling of estuaries are highly localised responses to the inter-related effects of sea-level fall, sediment supply and accommodation. Seaward movement of the coastline is most rapid in areas where progradation occurs as a consequence of muddy facies deposition at the coast, but it can be difficult to determine when and how often this occurred in locally specific, rather than regionally general terms.

These local conditions are likely to have had impacts on the availability of $A$. granosa. Previous work (e.g. Morrison 2003, 2010) indicates that shell mounds in Albatross Bay were reused and that deposition at individual mounds was not uniform in time. It also indicates that we might expect shell mound activity to vary in intensity within one region at centennial scales (see also Morrison 2003, 2010). This indicated to us the need to pay particular attention to the formation of the mounds rather than treat them as the intended consequence of single construction events. It was, however, unlikely that we would be able to explain shell mound formation as a result of a single environmental variable (e.g. the position of the coastline).

For these reasons we adopted the approach to shell mound investigation suggested by Stein and her colleagues. Stein (1992) emphasises how shell mounds should not be treated a priori as cultural deposits but must instead be considered as the result of a series of processes that have led to the accumulation and degradation of shell through a range of natural, as well as cultural, processes. Following Stein, we adopted a formational rather than an economic approach in our study. We excavated trenches into the mounds that provided us with the ability to construct a four-dimensional history of mound formation. This approach involved obtaining multiple radiocarbon determinations from an excavated section and OSL dating of the land surface upon which the mound was constructed. It also involved analyses that measured the physical structure of the deposit rather than interpreting results directly in economic terms. The results reported here come from a limited pilot study, and we are currently investigating a much larger number of mounds in our more extensive project.

Since shell mounds at Weipa were first studied, it has been obvious that they vary in size and shape. The use of the TLS, however, provides a way to quantify size, shape and orientation that enables precise measures of mound 
variability. The four mounds reported here vary considerably in shape and size. But it is not simply a matter of big and small mounds. How the volume of shell material is distributed in three dimensional space varies both in the shape of the mound and its orientation in relation to local topography. Mound shape, size and orientation are not simply products of people depositing shell but the outcome of multiple processes that have affected the mounds over time, both during the construction phases and since construction ceased. Use of the TLS enables us to measure variability in mound shape that results from the action of all these processes. The power of this approach is likely to best be seen when we analyse a much larger sample of mounds in our main study. The detailed survey data will contribute significantly to an understanding of how topographic location, processes of shell degradation and age of the mounds have influenced the mound shape that we see today.

Excavation of trenches into the mounds allows analyses that indicate highly variable records that are not apparent in the drawn stratigraphic sections. There is some evidence for more shell fragmentation at the top and base of the mounds (although even here there is variability) consistent with weathering at the surface after the mound was abandoned, and fragmentation at the base due to the weight of material pressing down from above, observations that are in line with earlier studies (Hiscock and Mowat 1993; Mowat 1994). But there is also considerable variability within the centre of the mounds. In mounds WPSM75, WPSM76 and particularly WPSM77, the predominance of larger shell fractions alternates with that of smaller shell fragments (see Figures 11-14). This may indicate periods when shell deposition ceased and shells were crushed by exposure to a variety of agents, including people, only to be buried when shell discard on the mound recommenced. If fragmentation does indicate a hiatus in accumulation, this occurred on a number of occasions within the span of time indicated by the radiocarbon determinations (see also Morrison 2010).

A model of multiple periods of shell accumulation followed by a hiatus is supported to some degree by the shell dissolution results. In general, there are increased levels of shell dissolution at the top and base of the mounds, reflecting water percolation down from the surface and groundwater saturation respectively. For some of the mounds, however, particularly WPSM77 but also WPSM66 (see Figures 15-18) there is evidence for multiple peaks in the dissolution index through the body of the mound. This pattern is consistent with the exposure of multiple surfaces that were subsequently buried when shell accumulation recommenced. There are also interesting differences in the values for the shell dissolution results partly related to the size and shape of the mounds but also likely related in some way to their topographic contexts.

Species diversity results also display variability throughout the mound deposits (Figures 19-32) although, like the TLS data, the power of these results will come from comparison among a much larger number of mounds than reported here. Species diversity is of course a function of the behaviour of the Aboriginal people who collected the shellfish, but it also reflects the local availability of species which in turn relates to local environmental conditions (cf. Bailey 1975b:VII:40-41; Meehan 1982:114-116). Although dominated by just one species, Anadara granosa, the results are suggestive of multiple shifts in the nature of the shellfish populations. There is, for instance, a shift in diversity in WPSM75 at the gap in mound use indicated by the hiatus in radiocarbon dates (Figure 20 and Table 7 ). It is tempting to now compare the results from the four mounds, looking for similarities in the age of shell fragmentation, dissolution and species diversity and then to relate these results to shifts in local and perhaps regional environment. However, such comparisons among only four mounds are premature. The results of the preliminary study are sufficient to indicate interesting variability in mound structure and content but given that there are more than 50 mounds in the Wathayn area alone, they are not yet sufficient to interpret this variability in terms of human responses to environmental change.

Three of the mounds (WPSM66, WPSM76 and WPSM77) have chronologies that place their construction at around 2750 cal BP. However, consistent with other studies, these mounds may have accumulated over decades or centuries. WPSM75 also accumulated over several centuries but, unlike the other mounds, there is evidence for a 300-year hiatus in deposition between 1100 and 1400 cal BP (Table 8). It is obviously essential that sufficient radiocarbon determinations are obtained to detect such gaps in accumulation. Too often in the past, mounds have been inadequately dated in terms of both the number of samples per mound and the selection of shells to date. Samples for dating need to be obtained from the full depth of the mounds and from multiple locations from the centre to the perimeter, as we have now incorporated into our sampling protocol for the larger project. Dating only shells collected near to the surface will in most cases only provide evidence of the timing of the most recent use of the mound.

Dating the underlying substrate is also an essential part of any analysis of the relationships between mound construction and past environmental changes. At Wathayn, the luminescence ages of the sediments beneath the mounds all pre-date the basal shell radiocarbon ages (Tables 7 and 9), providing an independent control on the timing of the commencement of shell accumulation at the various locations. Furthermore, the luminescence ages indicate a mid-Holocene age for the commencement of estuarine infilling with muddy sediments at this location. The luminescence ages of the sandy sediments beneath WPSM76 and WPSM77 are suggestive of a hiatus in infilling and progradation in the period 5000-4000 BP, indicated by local reworking of sandy sediments into a linear ridge parallel to the shoreline.

In all four cases, there is a time gap between the deposition of the substrate and the commencement of shell accumulation, which in the case of WPSM75 could be more than 4000 years. There are several possible explanations for the gap, including the inability to collect OSL samples close to the mound/substrate boundary because of the increased risk of rebleaching of the quartz grains in the sediments at or close to the pre-mound surface. One simple explanation may be the choice of location for shell discard by people in the past. Alternatively, there may be a time-lag between the stabilisation of the shoreline and the development of the 
A. granosa beds at this location. This explanation may be particularly true for WPSM76 and WPSM77, in that the postulated sandy beach ridge environment beneath these mounds may indicate the presence of estuarine conditions that may not have been suitable for the establishment and growth of $A$. granosa beds. More dates from mounds located on different landforms, and at different distances from the modern shoreline, are required to fully explore this pattern.

\section{Conclusions}

As indicated both by earlier studies (e.g. Morrison 2003, 2010) and the results of the dating programme and the analyses of shell mound composition reported here, mound shape is the end result of a complex mix of processes that include how often and how intensively mounds were used and reused, together with the nature of the shell populations people exploited and the postdepositional changes that have occurred over the centuries the mounds have existed. Any consideration of the form, number and location of mounds needs to take all of these processes into account. While intensive study of just four mounds at Wathayn has indicated considerable variability in the pattern of accumulation and weathering in both space and time, it is critical that the whole population of mounds is analysed before we can construct a narrative of Aboriginal interaction with the environment over the last few millennia.

The methods we chose, designed to inform on mound variability, have produced results consistent with the action of multiple processes that combined are responsible for the shell mounds that today are so apparent at Wathayn. The use of a suite of measurements made to determine the ages and duration of mound use, the composition of the shell matrix, the taphonomic status of the shells and their species diversity, together with the use of technologies that let us consider multiple aspects of mound size, shape and orientation, produce the types of results that are consistent with past studies that in sum indicate no one variable can explain shell mound presence.

We are currently gathering data from a much larger population of shell mounds along the north Embley River at Weipa. More data on its own will of course provide no guarantee of a better understanding of the past. But more data gathered with a view to documenting and then interpreting variability, measured using a set of parameters closely related to the formational history of the mounds, is very likely to provide a better understanding of human-environment interactions in the past. There are no quick answers in archaeology as in any other natural science. Nor should we look to leap directly from a small number of observations to large-scale behavioural or environmental explanations. Instead it is the detail that will provide the means to draw interesting socio-cultural inferences about the Aboriginal past and create the type of narrative that is of interest to the Aboriginal traditional owners at Wathayn, and elsewhere in northern Australia. It is a fascinating past about which to learn so it is worth taking the time and making the effort to record it in detail.

\section{Acknowledgements}

Research at Wathayn was jointly funded by a Linkage Projects Seeding Grant from Macquarie University and Rio Tinto Alcan Pty Ltd. We would like to acknowledge the senior traditional owner for Wathayn, Aunty Beatrice Gordon, for her support and enthusiasm for the project and all Wathayn traditional owners for making us welcome in their country. The project would not have been possible without the continued support of the Western Cape Communities Coexistence Agreement and the Napranum Aboriginal Shire Council. We thank Tim Mackrell (Department of Anthropology, The University of Auckland) for valuable assistance with fieldwork, particularly laser scanning and photography. Phil Toms (University of Gloucestershire Geochronology Laboratory) produced the luminescence dates, and Rhaelene Freeman (Macquarie University) undertook the sediment analyses. Finally, we thank Craig Sloss for helpful comments on a draft of the paper that helped to sharpen it up. Daniel Rosendahl and Patricia Bourke provided constructive reviews of the submitted manuscript. We also thank Sean Ulm and Mick Morrison for inviting us to contribute this paper to the special issue and for their suggestions for improvements to the manuscript. One of us (JS) has especially enjoyed many discussions about Weipa shell mounds with Mick over the years.

\section{References}

Ambrose, W.R. 1967 Archaeology and shell middens. Archaeology and Physical Anthropology in Oceania 2(3):169-187.

Anderson, A., M. Gagan and J. Shulmeister 2007 Mid-Holocene cultural dynamics and climatic change in the Western Pacific. In G.A. David, A.M. Kirk and H.S. Daniel (eds), Climate Change and Cultural Dynamics, pp.265-296. San Diego: Academic Press.

Bailey, G.N. 1975a The role of molluscs in coastal economies: The results of midden analysis in Australia. Journal of Archaeological Science 2(1):45-62.

Bailey, G.N. 1975b The Role of Shell Middens in Prehistoric Economies. Unpublished $\mathrm{PhD}$ thesis, University of Cambridge, Cambridge.

Bailey, G.N. 1977 Shell mounds, shell middens, and raised beaches in the Cape York Peninsula. Mankind 11(2):132143.

Bailey, G.N. 1983 Problems of site formation and the interpretation of spatial and temporal discontinuities in the distribution of coastal middens. In P.M. Masters and N.C. Fleming (eds), Quaternary Coastlines and Marine Archaeology: Towards the Prehistory of Land Bridges and Continental Shelves, pp.558-552. London: Academic Press.

Bailey, G.N. 1999 Shell mounds and coastal archaeology in northern Queensland. In J. Hall and I.J. McNiven (eds), Australian Coastal Archaeology, pp.105-112. Research Papers in Archaeology and Natural History 31. Canberra: ANH Publications, Department of Archaeology and Natural History, Research School of Pacific and Asian Studies, Australian National University.

Bailey, G.N. 2004 World prehistory from the margins: The role of coastlines in human evolution. Journal of Interdisciplinary Studies in History and Archaeology 1(1):39-50.

Bailey, G.N., J. Chappell and R. Cribb 1994 The origin of Anadara shell mounds at Weipa, north Queensland, Australia. Archaeology in Oceania 29(2):69-80. 
Bailey, G.N. and J. Parkington 1988 The archaeology of prehistoric coastlines: An introduction. In G.N. Bailey and J. Parkington (eds), The Archaeology of Prehistoric Coastlines: New Directions in Archaeology, pp.1-21. Cambridge: Cambridge University Press.

Beaton, J.M. 1985 Evidence for a coastal occupation time-lag at Princess Charlotte Bay (North Queensland) and implications for coastal colonization and population growth theories for Aboriginal Australia. Archaeology in Oceania 20(1):1-20.

Beresford, C. 2011 Understanding Human Behavioural Change and Shell Mound Location at Albatross Bay, Cape York, Australia. Unpublished MA thesis, Department of Anthropology, The University of Auckland, Auckland.

Bøtter-Jensen, L., V. Mejdahl and A.S. Murray 1999 New light on OSL. Quaternary Science Reviews 18(2):303-309.

Bourke, P.M., S. Brockwell, P. Faulkner and B. Meehan 2007 Climate variability in the mid to late Holocene Arnhem Land region, north Australia: Archaeological archives of environmental and cultural change. Archaeology in Oceania 42(3):91-101

Bronk Ramsey, C. 2009 Bayesian analysis of radiocarbon dates. Radiocarbon 51(1):337-360.

Broom, M.J. 1985 The Biology and Culture of Marine Bivalve Molluscs of the Genus Anadara. Manilla: International Centre for Living Aquatic Resources Management.

Chappell, J. and J. Grindrod 1984 Chenier plain formation in northern Australia. In B.G. Thom (ed.), Coastal Geomorphology in Australia, pp.197-231. Sydney: Academic Press.

Chappell, J., E.G. Rhodes, B.G. Thom and E. Wallensky 1982 Hydro-isostasy and the sea-level isobase of $5500 \mathrm{BP}$ in north Queensland, Australia. Marine Geology 49(1-2):8190.

Claassen, C. 1998 Shells. Cambridge: Cambridge University Press.

Cosgrove, R., J. Field and Å. Ferrier 2007 The archaeology of Australia's tropical rainforests. Palaeogeography, Palaeoclimatology, Palaeoecology 251(1):150-173.

Cribb, R. 1986 A preliminary report on archaeological findings in Aurukun Shire, western Cape York. Queensland Archaeological Research 3:133-158.

Crowley, G.M. 1995 Fire on Cape York Peninsula: Cape York Peninsula Land Use Strategy. Unpublished report to Office of the Co-Ordinator General of Queensland, Brisbane and Department of the Environment, Sport and Territories, Canberra.

Eggleton, R.A. and G. Taylor 2008 Effects of some macrobiota on the Weipa bauxite, northern Australia. Australian Journal of Earth Sciences 55(sup1):S71-S82.

Ford, P. 1989 Molluscan assemblages from archaeological deposits. Geoarchaeology 4(2):157-173.

Grayson, D.K. 1984 Quantitative Zooarchaeology: Topics in the Analysis of Archaeological Faunas. New York: Academic Press.

Haberle, S.G. and B. David 2004 Climates of change: Human dimensions of Holocene environmental change in low latitudes of the PEPII transect. Quaternary International 118-119:165-179.
Henri, O., A.F. Lotter and G. Lemcke 2001 Loss on ignition as a method for estimating organic and carbonate content in sediments: Repeatability and comparability of results. Journal of Paleolimnology 25:101-110.

Hiscock, P. and F. Mowat 1993 Midden variability in the coastal portion of the Kakadu region. Australian Archaeology $37: 18-24$.

Hughes, P. 1980 I dig dirt: Geomorphological methods in Australian archaeology. In I. Johnson (ed.), Holier Than Thou: Proceedings of the 1978 Kioloa Conference on Australian Prehistory, pp.3-17. Canberra: Department of Prehistory, Research School of Pacific and Asian Studies, Australian National University.

Hughes, P. 1983 Geoarchaeology in Australia. In G. Connah (ed.), Australian Field Archaeology: A Guide to Techniques, pp.109-117. Canberra: Australian Institute for Aboriginal Studies.

Lambeck, K. and M. Nakada 1990 Late Pleistocene and Holocene sea-level change along the Australian coast. Palaeogeography, Palaeoclimatology, Palaeoecology 89(12):143-176.

Lourandos, H. 1985 Intensification and Australian prehistory. In D.T. Price and J.A. Brown (eds), Prehistoric HunterGatherers: The Emergence of Cultural Complexity, pp.385423. Orlando: Academic Press.

Markey, B.G., L. Bøtter-Jensen and G.A.T. Duller 1997 A new flexible system for measuring thermally and optically stimulated luminescence. Radiation Measurements 27(2):83-89.

McGlone, M., A.P. Kershaw and V. Markgraf 1992 El Niño/Southern Oscillation climatic variability in Australasian and South American paleoenviromental records. In H.F. Diaz and V. Markgraf (eds), El Niño: Historical and Paleoclimatic Aspects of the Southern Oscillation, pp.435-462. Cambridge: Cambridge University Press.

Meehan, B. 1982 Shell Bed to Shell Midden. Canberra: Australian Institute of Aboriginal Studies.

Mitchell, S. 1993 Shell mound formation in northern Australia: A case study from Croker Island, northwestern Arnhem Land. The Beagle 10(1):179-192.

Morrison, M. 2003 Old boundaries and new horizons: The Weipa shell mounds reconsidered. Archaeology in Oceania 38(1):1-8.

Morrison, M. 2010 The Shell Mounds of Albatross Bay: An Archaeological Investigation of Late Holocene Production Strategies near Weipa, North Eastern Australia. Unpublished $\mathrm{PhD}$ thesis, Department of Archaeology, Flinders University, Adelaide.

Mowat, F. M. 1994 Size really does matter: Factors affecting shell fragmentation. In M. Sullivan, S. Brockwell and A. Webb (eds), Archaeology in the North, pp.201-210. Darwin: North Australia Research Unit, Australian National University.

Muckle, R.J. 1985 Archaeological Considerations of Bivalve Shell Taphonomy. Unpublished MA thesis, Department of Archaeology, Simon Fraser University, Vancouver.

Murray, A.S. and A.G. Wintle 2000 Luminescence dating of quartz using an improved single-aliquot regenerative-dose protocol. Radiation Measurements 32(1):57-73. 
Murray, A.S. and A.G. Wintle 2003 The single aliquot regenerative dose protocol: Potential for improvements in reliability. Radiation Measurements 37(4-5):377-381.

O'Connor, S. 1999 A diversity of coastal economies: Shell mounds in the Kimberley region in the Holocene. In J. Hall and I.J. McNiven (eds), Australian Coastal Archaeology, pp.37-50. Research Papers in Archaeology and Natural History 31. Canberra: ANH Publications, Department of Archaeology and Natural History, Research School of Pacific and Asian Studies, Australian National University.

Petchey F, S. Ulm, B. David, I.J. McNiven, B. Asmussen, H. Tomkins, N. Dolby, K. Aplin, T. Richards, C. Rowe, M. Leavesley and H. Mandui 2013 High-resolution radiocarbon dating of marine materials in archaeological contexts: Radiocarbon marine reservoir variability between Anadara, Gafrarium, Batissa, Polymesoda spp. and Echinoidea at Caution Bay, southern coastal Papua New Guinea. Archaeological and Anthropological Sciences 5:69-80.

Reeves, J.M. 2004 The Use of Ostracoda in the Palaeoenvironmental Reconstruction of the Gulf of Carpentaria, from the Last Interglacial until Present. Unpublished PhD thesis, School of Earth and Environmental Sciences, University of Wollongong, Wollongong.

Reimer P.J., M.G.L. Baillie, E. Bard, A. Bayliss, J.W. Beck, P.G. Blackwell, C. Bronk Ramsey, C.E. Buck, G.S. Burr, R.L. Edwards, M. Friedrich, P.M. Grootes, T.P. Guilderson, I. Hajdas, T.J. Heaton, A.G. Hogg, K.A. Hughen, K.F. Kaiser, B. Kromer, F.G. McCormac, S.W. Manning, R.W. Reimer, D.A. Richards, J.R. Southon, S. Talamo, C.S.M Turney, J. van der Plicht and C.E. Weyhenmeyer 2009 IntCal09 and Marine09 radiocarbon age calibration curves, 0-50,000 years cal BP. Radiocarbon 51(4):1111-1150.

Rhodes, E.G. 1980 Modes of Holocene Progradation, Gulf of Carpentaria. Unpublished $\mathrm{PhD}$ thesis, Australian National University, Canberra.

Rodríguez-Gonzálvez, P., J. Mancera-Taboada, D. GonzálezAguilera, Á. Muñoz-Nieto and J. Armesto 2012 A hybrid approach to create an archaeological visualization system for a Palaeolithic cave. Archaeometry 54(3):565-580.

Roth, W.E. 1901 Food: Its Search, Capture and Preparation North Queensland Ethnography Bulletin 3. Brisbane: Government Printer.

Shiner, J. and M. Morrison 2009 The contribution of heritage surveys towards understanding the cultural landscape of the Weipa Bauxite Plateau. Australian Archaeology 68:52-55.

Shulmeister, J. and B.G. Lees 1992 Morphology and chronostratigraphy of a coastal dunefield; Groote Eylandt, northern Australia. Geomorphology 5(6):521-534.

Shulmeister, J. and B.G. Lees 1995 Pollen evidence from tropical Australia for the onset of an ENSO-dominated climate at c. 4000 BP. The Holocene 5(1):10-18.
Sloss, C.R., B.G. Jones and C.V. Murray-Wallace 2005 Holocene sea level fluctuations and the sedimentary evolution of a barrier estuary: Lake Illawarra, New South Wales, Australia. Journal of Coastal Research 21:943-959.

Sloss, C.R., B.G. Jones and C.V. Murray-Wallace 2007 Holocene sea-level change on the southeast coast of Australia: A review. The Holocene 17:1001-1016.

Sloss, C.R., C.V. Murray-Wallace and B.G. Jones 2006 Aminostratigraphy of two Holocene wave-dominated barrier estuaries in southeastern Australia. Journal of Coastal Research 22:113-136.

Smith, M.A. 1996 Prehistory and human ecology in Central Australia: An archaeological perspective. In S.R. Morton and D.J. Mulvaney (eds), Exploring Central Australia: Society, the Environment and the 1894 Horn Expedition, pp.61-73. Sydney: Surrey Beatty.

Stein, J.K. 1992 Deciphering a Shell Midden. San Diego: Academic Press.

Stone, T. 1995 Shell mound formation in coastal northern Australia. Marine Geology 129:77-100.

Toms, P.S. 2011 Optical Dating of Sediments, Weipa, Australia. Unpublished report, University of Gloucestershire Geochronology Laboratories.

Turney, C.S.M. and D. Hobbs 2006 ENSO influence on Holocene Aboriginal populations in Queensland, Australia. Journal of Archaeological Science 33(12):1744-1748.

Ulm, S., F. Petchey, G.E. Jacobson and D. Rosendahl in press Pre-bomb marine radiocarbon reservoir variability in the eastern Gulf of Carpentaria, Queensland, Australia. Queensland Archaeological Research 17.

Wanner, H., J. Beer, J. Bütikofer, T.J. Crowley, U. Cubasch, J. Flückiger, H. Goosse, M. Grosjean, F. Joos, J.O. Kaplan, M. Küttel, S.A. Müller, I. Colin Prentice, O. Solomina, T.F. Stocker, P. Tarasov, M. Wagner and M. Widmann 2008 Mid- to late Holocene climate change: An overview. Quaternary Science Reviews 27(19-20):1791-1828.

Woodroffe, C.D. and J. Chappell 1993 Holocene emergence and evolution of the McArthur River Delta, southwestern Gulf of Carpentaria, Australia. Sedimentary Geology 83(34):303-317.

Wright, R.V.S. 1964 Probing Cape York's past. Hemisphere 8(7):12-16.

Wright, R.V.S. 1971 Prehistory in Cape York Peninsula. In D.J. Mulvaney and J. Golson (eds), Aboriginal Man and Environment in Australia, pp.133-140. Canberra: Australian National University Press.

Wyrwoll, K-H. and G.H. Miller 2001 Initiation of the Australian summer monsoon 14,000 years ago. Quaternary International 83-85:119-128. 
